\title{
AVALIAÇÃO FISIOTERAPEUUTICA EM PACIENTES COM TUBERCULOSE PULMONAR SOB REGIME DE INTERNAÇÃO
}

SILVIA DE OLIVEIRA ARPIANI

Dissertação apresentado ao Departamento

de Epidemiologia da Faculdade de Saúde Pública

da Universidade de São Paulo

Nivel - Mestrado

Área de concentração: Epidemiologia

Orientadora: Prof .Dra. Margarida M. M. B. de Almeida

São Paulo

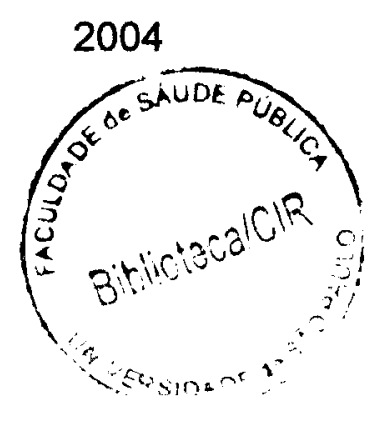


"Em ciêncía não existe um erro tão grosseiro que, amanhã ou depois, sob alguma perspectiva, não pareçaprofético."

Jean Rostand 
3

DEDICATÓRIA

Dedico este trabalho a todos pacientes pois é graças a eles que sou felize realizada em ser Fisioterapenta.

Dedico também, aos meus alunos que me fazem diariamentequerer ser melhor.

E dedico a minha "Familia Querida" por confiareme acreditarem no meu sonho. 


\section{AGRADECIMENTO}

Gostaria de agradecer ao men marido Ricardo, aos meus pais Waldomiro e Ingrid e irmãos Sandra, Paulo, Maritia e Cecilia pela dedicação, compreensão e princípalmente paciência.

Agradecer minha orientadora Profa. Margarida pela força, conhecimento e amizade nestes anos de elaboração deste trabalho.

As minhas coordenadoras Fernanda Amaral e Marta Damasceno, agradecer por compreender meus momentos de ausêncía.

Agradecer ao Prof Péricles, Profa Helenice e Profa. Cleide pelas sugestões e correções.

Aos mens amigos Zuleika, Fernanda, Ivan e Alessandrapelo apoio e incentivo.

E por fim, agradecer aos hospitais e pacientes deste estudo pelo consentimento e por tornar este sonho realidade.

Muito obrigado! 


\section{RESUMO}

ARPIANI SO. Avaliação Fisioterapêutica em Pacientes com Tuberculose Pulmonar sob Regime de Internação. São Paulo; 2003. [Dissertação de Mestrado - Faculdade de Saúde Pública da USP].

Introdução. A tuberculose pulmonar é uma doença para a qual no decorrer do tempo muitos tratamentos foram usados na tentativa de conseguir o seu controle. $\mathrm{O}$ advento dos quimioterápicos, em meados de 1940, que associados à melhoria de condições de vida fez com que ocorresse um decréscimo acentuado do número de óbitos, principalmente em paises desenvolvidos. Entretanto, ainda hoje existem problemas em relação ao controle da doença. Algumas questões surgem em relação à prevenção, tratamento e controle. Um dos aspectos questionados neste trabalho é a necessidade do repouso, que por muito tempo foi utilizado e que continua sendo apesar de existirem vários estudos sobre os efeitos deletérios do repouso prolongado. Objetivo. Este trabalho visa verificar alterações relacionadas com o repouso prolongado em paciente com tuberculose pulmonar internados em um hospital de longa permanência e outro de curta permanência na cidade de São Paulo. Métodos. Foi realizado um estudo transversal descritivo, por meio de um questionário de avaliação fisioterapêutica especificamente elaborado para o estudo, compreendendo avaliaçōes através de palpações, mensuraçōes usando aparelhos especificos e entrevistas com perguntas abertas e fechadas. Resultados. Foi observado que $40 \%$ dos indivíduos 
encontravam-se desnutridos, $40 \%$ apresentavam déficit de marcha, $49 \%$ apresentavam-se taquicárdicos, $60 \%$ apresentavam-se com expansibilidade diminuída e $56 \%$ apresentavam algum grau de dor. Conclusões. $\mathrm{Na}$ variação dos sistemas observou-se que no sistema gastrointestinal houve a maior variação positiva $(+0.21)$. No sistema cardiovascular houve a maior variação negativa $(-0.16)$, observou-se ainda que $52 \%$ dos individuos analisados apresentaram algum grau de imobilismo, sugerindo que o repouso adotado como prática terapêutica pode ser prejudicial nesta população.

Descritores: Tuberculose Pulmonar. Repouso. Fisioterapia. Imobilismo. 


\section{SUMMARY}

\section{ARPIANI SO. Evaluation Phisiotherapy in Patients with Lung Tuberculosis under Regime of Internment. São Paulo; 2003. [Dissertação de Mestrado - Faculdade de Saúde Pública da USP].}

Introduction. A long time many treatment had been used to obtain the control the lung tuberculosis. The advent of chemeotherapy, around 1940 years, that associate to the improvement of life conditions results in a accented reduction of death, especialy in developed countries. However, nowadays there are problems to about to control this disease. Some questions arise to about the prevention, treatment and control. One of the aspects questioned in this research is the necessity of the rest, that for a long time was and continues used although to have some research to about the deleterious effects of the longest rest. Objective. This research to aims to verify alterations related with the longest rest in patient with lung tuberculosis admitted to the long permanence hospital and another one in short permanence hospital in São Paulo city. Methodos. A descriptive transversal research was executed, through phisiotherapist evaluation questionnaire specifically elaborated for this research, with evaluation through palpation, mensuration, using especific equipments and interviews with open and close questions. Results. $40 \%$ of the patients were with malnutricion, $40 \%$ were with walk problems, $49 \%$ were with high cardiac frequency, $60 \%$ were with low expansibility of chest and $56 \%$ were with some 
degree of pain. Conclusions. Gastrointestinal system had the biggest positive variation $(+0.21)$. Cardiovascular system had the biggest negative variation $(-0.16), 52 \%$ of patients had some degree of immobilism, suggesting that the adopted rest as therapeutical practical could be harmful in this population.

Key words: Lung Tuberculosis. Bed Rest. Phisiotherapy. Immobilism. 


\section{LISTA DE TABELAS, GRÁFICOS E FIGURAS}

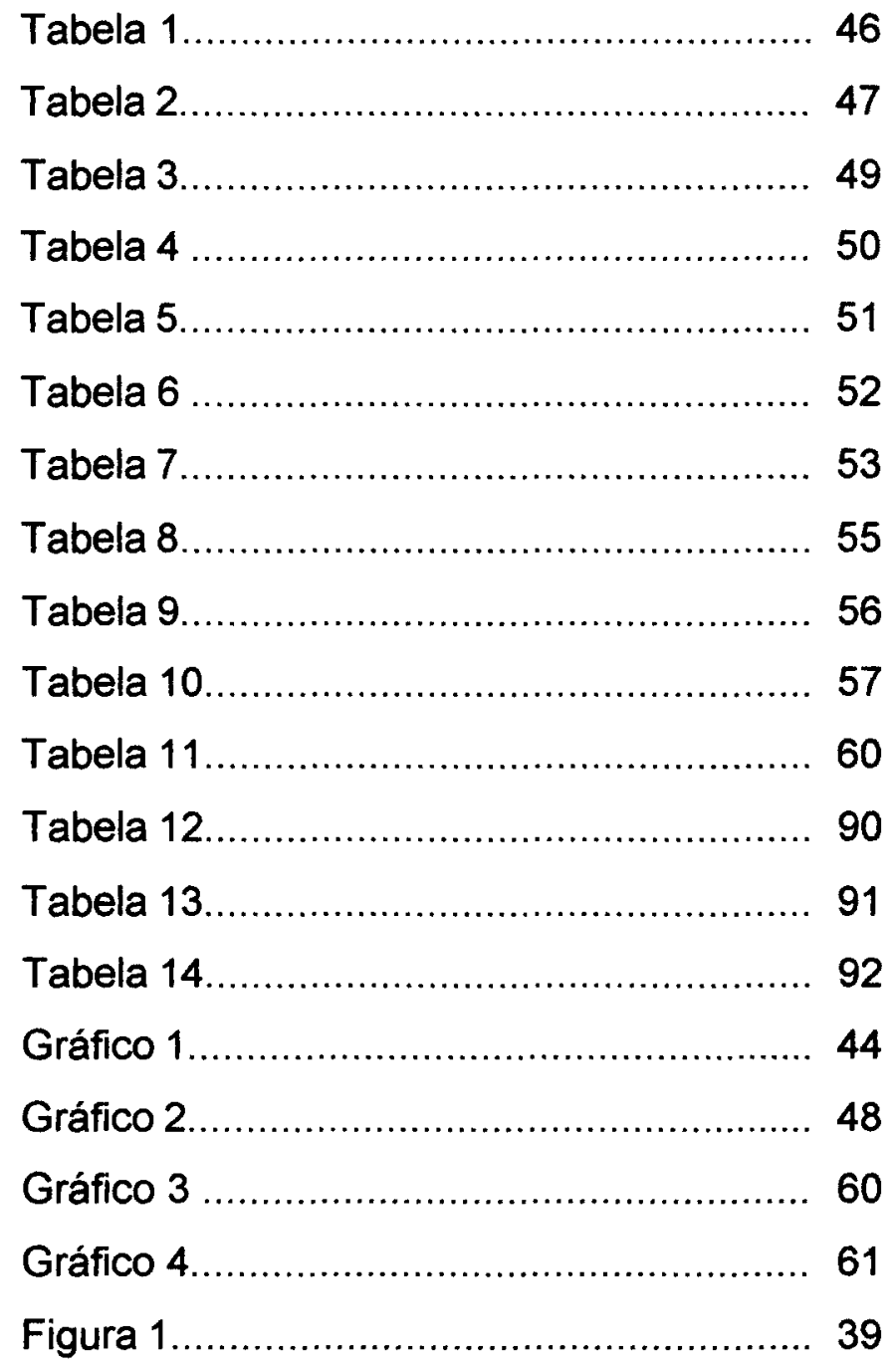




\section{ÍNDICE}

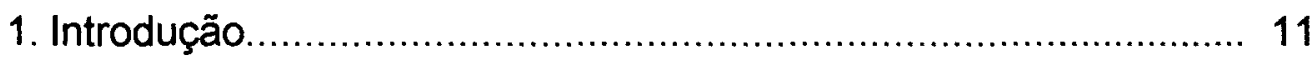

1.2. Síndrome do Imobilismo.................................................... 17

1.2.1. Sistema Músculo-esquelético........................................... 18

1.2.2. Sistema Cardiovascular........................................................ 21

1.2.3. Sistema Respiratório ................................................... 23

1.2.4. Sistema Gastrointestinal.................................................. 23

1.2.5. Sistema Geniturinário........................................................ 24

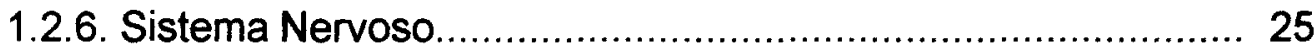

1.2.7. Sistema Metabólico e Endócrino......................................... 25

1.2.8. Tuberculose e Repouso................................................... 26

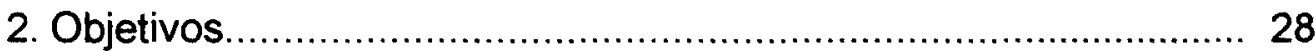

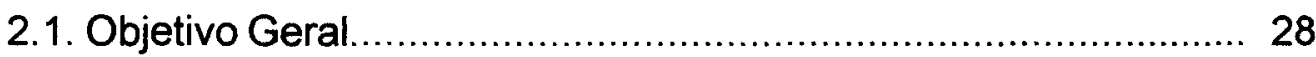

2.2. Objetivo Especifico............................................................ 28

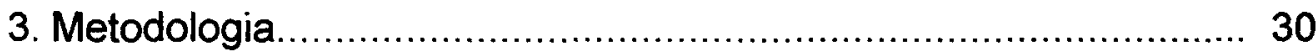

3.1. Delineamento do Estudo..................................................... 30

3.2. População Estudada e Local de Estudo................................ 30

3.3. Instrumento de Pesquisa ...................................................... 32

3.4. Variáveis de Estudo........................................................... 32

3.4.1. Variáveis Dependentes.................................................... 33

3.4.2. Caracterização dos Pacientes............................................ 41

3.5. Análise dos Dados ........................................................... 42

4. Resultados e Discussão........................................................ 44

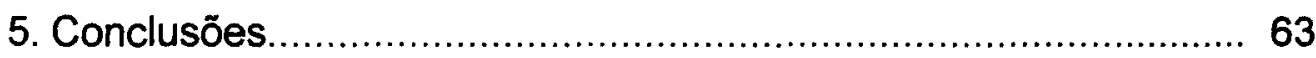

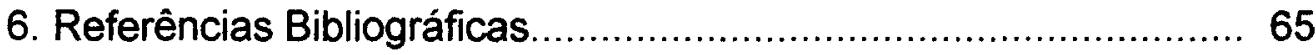

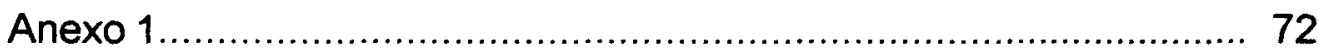

Anexo 2

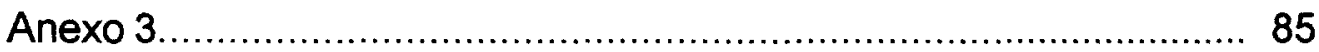

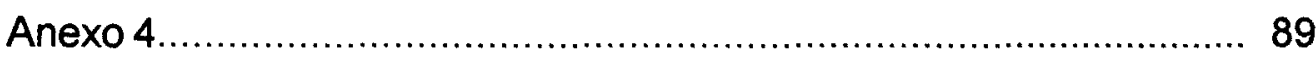




\section{INTRODUÇÃO}

A tuberculose pulmonar é considerada uma das doenças mais antigas da civilização, fazendo muitos acreditarem que esta surgiu juntamente com o homem.

No entanto, a comprovação cientifica mais segura da tuberculose vem de múmias encontradas na região de Tebas, onde foram achadas 44 múmias, bem preservadas, datando de 3700 a 1000 a.C., datação esta feita com o carbono 14. A maioria dessas múmias vem da $21^{a}$ Dinastia do Egito, mostrando que muitos Faraós tiveram tuberculose e morreram extremamente jovens (ROSEMBERG 1999).

Assim como no Egito, a tuberculose fez vítimas por todo mundo, mas a grande epidemia da tuberculose, chamada de "Peste Branca", ocorreu entre o final do século XVIII e início do século XIX, juntamente com a Revolução Industrial, na Inglaterra, que posteriormente estendeu-se por toda Europa (ROSEMBERG 1999).

Para dimensionar o tamanho da catástrofe causada pela tuberculose, em Paris, em meados do século XIX os óbitos por tuberculose atingiram $80 \%$ da mortalidade geral e na segunda metade do século XIX, a mortalidade por tuberculose nas capitais Européias ia de 400 a 600 por 100 mil/habitantes, atingindo $30 \%$ da mortalidade geral (ROSEMBERG 1999).

A tuberculose atingiu outros hemisférios através das conquistas territoriais, das colonizações, onde o homem civilizado chegou, levou 
também 0 bacilo da tuberculose. Assim aconteceu no Brasil (ROSEMBERG 1999).

Muitos tratamentos surgiram na tentativa de controlar a doença. Com o surgimento dos quimioterápicos, em meados de 1940, que associados à melhoria de condições de vida levaram a um decréscimo no número de óbitos, principalmente em paises desenvolvidos, levando muitos a vislumbrarem a erradicação da tuberculose. Este declínio no número de óbitos também ocorreu nos países subdesenvolvidos, onde apesar desta queda, a tuberculose nunca deixou de ser um problema de saúde pública (FAIRCHILD e OPPENHEIMER 1998).

O tratamento e diagnóstico da tuberculose pareciam ter alcançado seus limites, pois já apareciam quedas importantes no número de óbitos, reflexo do tratamento. Esta queda gerou um descaso que associado à falta de prioridades políticas e a eclosão da epidemia de HIV, potencializou a tuberculose (FAIRCHILD e OPPENHEIMER 1998). Este aumento no número de casos nos mostra que ela é uma doença que merece nosso respeito e atenção.

"Atenção nova para uma doença velha, médicos especialistas e profissionais de saúde pública esperam trazer novamente a tuberculose sob controle" (RUMPF 1992)

HOLME, 1998, afirma que grande parte deste acréscimo no número de casos está relacionada com o despreparo de profissionais da saúde, isto porque: 
"A tuberculose desapareceu dos currículos escolares médicos tão depressa quanto o fez dos programas de pesquisa farmacéutica e prioridades políticas" e este despreparo fez "a cidade de Nova lorque olhar para a Tanzânia para descobrir como controlar sua própria explosão de tuberculose" (HOLME 1998).

O recente ressurgimento da tuberculose nos países desenvolvidos trouxe grande preocupação, principalmente relacionados aos pacientes que não completam a terapia prescrita, o que os tornam muitas vezes multidrogas resistentes (MDR). Esta preocupação levou a OMS, em 1993, declarar a tuberculose como emergência global e vem fazendo desde então intensivos esforços apoiados pelo Banco Mundial, com o objetivo de controlar a doença (HOLME 1998 e REICHMAN 1999).

DUBOS e DUBOS, 1992 em seu livro cita que em 1854 BREHMER estabeleceu e instituiu para o tratamento da tuberculose as montanhas Gorbersdorf na Silesia, começava o movimento para os sanatórios, que ainda era uma noção errada que tinha levado BREHMER a procurar a cura da tuberculose nas montanhas. Ele tinha sido impressionado pelo fato que na necrópsia, foi freqüentemente encontrado, um coração pequeno e com paredes musculares fracas, e atribuiu este defeito a circulação pobre que é o resultado da doença no tecido pulmonar, concluiu que este pudesse ser corrigido por uma atividade física intensa, uma vida saudável e altas altitudes. Porém, logo descobriu que exercícios vigorosos eram prejudiciais e começou a reduzir as atividades dos seus pacientes. DETTWEILER que tinha sido um 
paciente e um aluno de BREHMER ficou mais impressionado com os efeitos benéficos do repouso. Em Falkenstein ele abriu seu próprio sanatório, em 1876, onde aconselhava aos pacientes que descansassem por meses em varandas ao ar livre (DUBOS e DUBOS 1992).

Durante duas décadas o regime adotado para o tratamento e cura da tuberculose foi o repouso absoluto e o ar livre. Este foi utilizado na Europa e por toda parte. $O$ paciente foi transferido de um quarto sufocante, aquecido, firmemente fechado para qualquer lugar e que dispunha de uma atmosfera sem contaminação de civilização. Os Alpes suiços foram logo reconhecidos como um lugar ideal para inalar "ar puro", e os relatos fervorosos de médicos ingleses estabeleceram a reputação internacional destes como estações de tratamento (DUBOS e DUBOS 1992).

Os tratamentos propostos para tuberculose evoluíram durante as últimas décadas tornando-os cada vez mais eficientes, todavia na medicina ainda imperam muitos "ditos populares" e "tabus" que apesar de não terem embasamento científico continuam sendo adotados como verdades absolutas.

Estes "tabus" e "ditos populares" vem da própria história da tuberculose, onde os profissionais da época anterior à quimioterapia, no desespero de conter a doença adotavam práticas bizarras que aos nossos olhos parecem pouco cientificas, como por exemplo, infusão de rosas com mel, sangrias, purgativos entre outras. 
Por quase 3 milênios, desde as primeiras referências sobre tratamento da tísica (civilizaçōes Hindu e Persa), passando por Hipócrates, as escolas de Cós e Cnide na Grécia, depois Alexandria, Galeno em Roma, Salermo, Montpellier, a Renascença até a primeira metade do século $X X$, recomendou-se repouso e super alimentação, enfeixados modernamente sob a denominação de regime higienodietético. Climas amenos também foram recomendados. A mistica do ar das montanhas, no final do século $\mathrm{XIX}$, aumentou as indicações de helioterapia, que já vinham sendo feitas, sobretudo para as formas ósseas (ROSEMBERG 1999).

O repouso começa deixar de ser absoluto após o trabalho de Madras, na India, que através de um ensaio clínico controlado foi realizado para comparar o efeito de 12 meses de quimioterapia em dois grupos de pacientes: um grupo tratou sob as boas condiçōes de um sanatório, e o outro grupo era de indivíduos pobres tratados no seu domicilio (TOMAN 1979).

Os resultados, apesar de boa acomodação, cuidados, dieta rica, e repouso prolongado, não foram superior aos pacientes tratados em casas superpovoadas que tinham uma dieta pobre, menor repouso e que freqüentemente trabalhavam muitas horas (TOMAN 1979).

Foi este estudo que determinou a interrupçäo dramática de internações em sanatórios para tratamento ambulatorial como uma política geral (TOMAN 1979). 
Atualmente a área da saúde tem avançado de forma espetacular através da tecnologia e estudo do genoma, criando novas expectativas para o diagnóstico, tratamento e controle de diversas doenças, inclusive da tuberculose, contudo ainda existem muitas perguntas sem respostas, como por exemplo, sobre a necessidade do repouso.

Em conversas informais, muitos médicos quando questionados sobre a justificativa para o repouso absoluto no tratamento da tuberculose, afirmaram que a disseminação broncogênica nesta doença é diferente de outras doenças pulmonares, e consideram que a tuberculose teria uma disseminação canalicular (através dos poros de Khon e canais de Lambert) e que qualquer aumento de fluxo sangüíneo (por exemplo, através de atividade física) poderia aumentar a chance de disseminação broncogênica elou hematogênica, piorando o prognóstico do paciente, apesar de não existir nenhum relato recente de tal ocorrência, mesmo assim ainda é preconizado o repouso, talvez não da forma rigorosa que foi utilizado na época do regime higienodietético, mas com algumas restriçōes. A motivação para este estudo foi à contra-indicação absoluta da fisioterapia, principalmente a fisioterapia respiratória em pacientes internados com tuberculose pulmonar, tendo em vista as complicações do repouso.

Um exemplo disto vem da afirmação de CAVALCANTI (1935) que diz: "O tuberculoso que não faz repouso direito raramente se cura" ou ainda, REICHMAN, 1999, que cita um artigo de 1948 (autor desconhecido) que diz o seguinte "em poucas infeç̧öes é assim tão 
difícil de avaliar os resultados do tratamento como na tuberculose pulmonar, com seus quadros clínicos variados e curso imprevisível. As recuperações notáveis podem ocorrer sem nenhum tratamento, apenas - REPOUSO". Diante destas afirmações, pouco se estudou sobre o benefício do repouso, nos pacientes com tuberculose, apesar de muitas pesquisas avançarem sobre os efeitos deletérios do repouso prolongado, independentemente da doença ou do motivo que tenha levado o indivíduo a fazer o repouso.

\subsection{SINDROME DO IMOBILISMO}

Hipócrates foi o primeiro a afirmar que o exercício dá firmeza ao corpo, ao passo que a inatividade leva a deterioração. Baseados na história médica primitiva, muitos médicos advogam que a atividade e o movimento são ferramentas úteis na preservação do bem estar físico e mental. Porém HILTON, em 1863, e mais tarde THOMAS, JOHNS apud DELISA e col (1992) influenciaram profundamente a atitude dos clínicos com respeito à atividade, promovendo o descanso no leito e a imobilização como um princípio básico na cura tecidual. A atitude de "Descanse até estar curado" prevaleceu na medicina ocidental durante as quatro primeiras décadas do século XX (DELISA 1992; HALAR e BELL 1994 e CONVERTINO e col 1997). 
A prática atual de mobilização precoce começou depois da II Guerra Mundial e foi promovida pelos estudos de DEITRICK e col, 1948, que promoveram estudos em indivíduos normais, demonstrando os efeitos fisiológicos do repouso prolongado, onde comprovaram diversas alterações adversas que superam os efeitos terapêuticos do repouso.

O avanço nas viagens espaciais, nos anos 60 , serviu de impulso para estudos sobre o repouso e ausência de gravidade.

A imobilidade tem prevalência alta e é freqüentemente ignorada pelo médico principalmente no cuidado do idoso. As complicações relacionadas com imobilismo constituem significantes problemas em instituições de longa permanência, e esta requer cuidados médicos intensivos com implicaçōes financeiras (SELIKSON e col 1988).

É comumente aceito hoje em dia que a inatividade pode causar efeitos adversos em múltiplos órgãos e sistemas e isto caracteriza a Síndrome do Imobilismo. Os sistemas mais acometidos são músculoesquelético, cardiovascular, respiratório, gastrointestinal, geniturinário, nervoso, metabólico e endócrino.

\subsubsection{Sistema Músculo-esquelético}

O primeiro sistema acometido é o sistema músculo-esquelético que funciona como um desencadeador de um efeito em cascata em forma de um ciclo vicioso. 
BOOTH, 1982, indica que a primeira alteração ocorre na sintese e na degradação das proteínas contráteis do músculo, actina e miosina, quando um músculo não é utilizado, a velocidade da degradação das proteínas contráteis ocorre com maior rapidez que sua reposição, a conseqüência é a atrofia muscular. A diminuição da sintese protéica, que já é observada na sexta hora, após o início do repouso total no leito, é provavelmente a primeira causa da atrofia muscular.

No repouso absoluto e prolongado no leito, um músculo perderá 10 a $15 \%$ de sua força por semana, ou aproximadamente 1 a $3 \%$ por dia, ou seja, em repouso no leito por 3 a 5 semanas, um indivíduo perderá metade da sua força muscular. Em 2 meses o volume do músculo poderá diminuir para a metade de seu tamanho original (CRESS e col 1968; MOFFROID e col 1993 e SARAIVA 1996).

A fraqueza e a atrofia dos músculos terá como conseqüência à presença de dores musculares, lombalgia, dificuldades em subir escadas, deambulação prolongada, realização de atividades da vida diária, instabilidade na marcha e como conseqüência à queda e/ou medo de cair, fazendo com que o paciente permaneça por mais tempo na cama, desencadeando desta forma a cascata de eventos ou alterações em outros sistemas, que por sua vez, faz com que o paciente fique por mais tempo na cama, estabelecendo um ciclo vicioso.

Na posição deitada a atividade muscular é mínima, o que pode levar a contratura miogênica do tipo extrínseca, principalmente da 
musculatura antigravitacional, sendo muito comum aparecer como um dos primeiros sintomas do imobilismo a lombalgia (LI e BOMBARDIER 2001).

Segundo Oliveira e colaboradores, 1999, podem ocorrer ainda algumas alterações musculares tais como:

$\checkmark$ Diminuição no nível de glicogênio e ATP, diminuindo a resistência (endurance);

$\checkmark$ Uma diminuição no fluxo sanguíneo pode levar a uma baixa tolerância ao ácido lático e débito do oxigênio que terá como conseqüência uma diminuição na capacidade oxidativa;

$\checkmark$ Diminuição da síntese protéica como mencionado anteriormente;

$\checkmark$ Atrofia das fibras musculares tipos I e II;

$\checkmark$ Diminuição da área de secção transversal;

$\checkmark$ Diminuição de torque;

$\checkmark$ Incoordenação pela fraqueza generalizada, resultando em má qualidade de movimento.

Dentro ainda do sistema músculo-esquelético ocorrem alteraçōes em outras estruturas, como por exemplo tecido articular que devido a uma diminuiçăo ou ausência de movimento faz com que ocorra uma diminuição do líquido sinovial e uma atrofia da cartilagem com desorganização celular nas inserções ligamentares, proliferação do tecido fibrogorduroso e conseqüentemente levam ao espessamento da sinóvia e fibrose capsular (OLIVEIRA e col 1999). 
CARR e KENNEY, 1992, afirmam que o posicionamento articular é fundamental em indivíduos acamados principalmente em pacientes neurológicos, para se evitar futuras contraturas miogênicas e/ou artrogênicas e manter a função do membro acometido.

Já no tecido ósseo devido a uma diminuição das forças aplicadas sobre o osso pela tração do tendão e a força da gravidade, ocorre uma diminuição da massa óssea total, conseqüência do aumento da atividade osteoclástica e diminuição da atividade osteoblástica, aumento da excreção urinária de hidroxiprolina e aumento da excreção de cálcio, com um pico em torno de 16 semanas (máxima atividade osteoclástica) (HOLICK 2000 e BLOOMFIELD 1995).

A alteração que mais comumente chama a atenção da equipe ou do familiar sobre a necessidade de suspender ou diminuir o repouso são quando aparecem as temidas úlceras de decúbito que por sua vez surgem devido à pressão que aliado a uma diminuição de trofismo e exposição de proeminências óssea mais idade, umidade, estado nutricional, alterações metabólicas e edemas tem como resultado um grande problema (CRESS e col 1968; BONNER 1969; DELISA e col 1992; HALAR e BELL 1994; SARAIVA 1996 e OLIVEIRA e col 1999).

\subsubsection{Sistema Cardiovascular}

Manter-se em posição ortostática aumenta o consumo de energia (representando $19 \%$ de energia gasta) em comparação ao repouso. Já 
durante a locomoção ou atividade física, o metabolismo muscular aumenta 50 a 100 vezes, e o suprimento sangüineo aumenta 15 a 20 vezes, o que leva a uma forte resposta cardiopulmonar (HALAR e BELL 1994).

Já no indivíduo em repouso, a falta de ação gravitacional leva a uma diminuição da pressão hidrostática, fazendo com que 500 a $700 \mathrm{ml}$ de sangue retornem ao lado direito do coração, aumentando o volume sangüíneo na região central, provocando as respostas dos baroreceptores de alta pressão, levando a uma hipotensão ortostática (HALAR e BELL 1994).

Estas alterações nas pressōes resultam em diminuição na liberação do hormônio antidiurético, o que causa grande diurese, resultando em uma perda de 8 a $12 \%$ do volume de plasma durante as primeiras duas semanas de repouso no leito. Já na $2^{a}$ a $4^{a}$ semana esta perda pode chegar de 15 a 20\% (HALAR e BELL 1994).

Com o aumento da diurese e redução do volume plasmático, a viscosidade sangüínea aumenta e associada à estase venosa, que ocorre pela diminuição de contração dos músculos dos membros inferiores, se estabelecem 2 fatores da Tríade de Virchow: estase venosa e aumento da viscosidade do sangue. A tríade de Virchow, mesclam três elementos em maior ou menor grau resultando na formação do coágulo: estase venosa, lesão endotelial e aumento da viscosidade sanguinea, aumentando a chance de problemas tromboembólicos (OLIVEIRA e col 1999). 


\subsubsection{Sistema Respiratório}

Outro sistema acometido pelo repouso é o sistema respiratório. Segundo DELISA e col, 1992, o volume corrente, volume minuto, capacidade respiratória máxima, capacidade vital e a capacidade residual funcional, estarão diminuídos cerca de 25 a $50 \%$ no imobilismo.

A função respiratória está comprometida porque o movimento diafragmático fica diminuído no decúbito dorsal, assim como a expansão torácica. Além disso, existe uma diminuição da força dos músculos intercostais e da mobilidade nas articulações costovertebrais e costocondrais. Por esses motivos, a respiração torna-se superficial, causando um aumento relativo de dióxido de carbono nos alvéolos que levará a um aumento na frequêencia respiratória, dificultando também o "clearance" mucociliar favorecendo o aparecimento de atelectasias e/ou pneumonias (CRESS e col 1968).

\subsubsection{Sistema Gastrointestinal}

O individuo em repouso também terá alteraçōes no sistema gastrointestinal, devido à falta de movimento e estímulos, sofrerá perda de apetite, redução no peristaltismo, diminuição na absorção de nutrientes, contração esfincteriana, atrofia da mucosa e das glândulas 
intestinais e constipação. Outro fator também relevante que deve ser considerado é o pudor e a dificuldade para evacuar na frente de outras pessoas ou em comadres, fraldas ou simplesmente necessitar de algum tipo de auxilio, fora à posição antigravitacional que dificulta o esvaziamento intestinal (CRESS e col 1968; BONNER 1969; DELISA e col 1992; HALAR e BELL 1994; SARAIVA 1996 e OLIVEIRA e col 1999).

\subsubsection{Sistema Geniturinário}

No sistema geniturinário, a falta de ação gravitacional diminui a fixação de cálcio no osso (podendo evoluir para osteoporose), levando a uma hipercalcemia e a um esvaziamento incompleto da bexiga, podendo resultar assim em cálculos renais e proliferação de bactérias que podem evoluir para infecção do trato urinário. Não esquecendo, assim como no sistema gastrointestinal, do pudor e da dificuldade em urinar em recipientes apropriados (papagaio, uripen, comadres e sondas) ou mesmo em fraldas (CRESS e col 1968; BONNER 1969; DELISA e col 1992; HALAR e BELL 1994; SARAIVA 1996 e OLIVEIRA e col 1999). 


\subsubsection{Sistema Nervoso}

São poucos os estudos que mostram a relação existente entre o imobilismo e a organização central do comando postural, em contrapartida a privação sensorial é um pouco mais conhecida (SARAIVA 1996).

A falta de estimulos ambiental, físico, mental e social, pode levar a uma depressão, irritabilidade e diminuição da tolerância à dor, fazendo com que o indivíduo permaneça por mais tempo no leito mesmo porque este irá ter uma diminuição da coordenação e equilíbrio (CRESS e col 1968; BONNER 1969; SARAIVA 1996; HALAR e BELL 1994 e OLIVEIRA e col 1999).

\subsubsection{Sistema Endócrino e Metabólico}

As mudanças endócrinas que ocorrem com a inatividade, podem causar respostas diferentes quanto aos hormônios e enzimas, podendo não ser detectadas na clínica do paciente, nos primeiros dias de imobilismo. Uma vez instalada a reabilitação levará mais tempo para ser alcançada (CRESS e col 1968; BONNER 1969; SARAIVA 1996; HALAR e BELL 1994 e OLIVEIRA e col 1999).

Isto vale também para o sistema metabólico, que tem início lento e um período de recuperação também lento, apesar do reinício da 
mobilização (CRESS e col 1968; BONNER 1969; SARAIVA 1996; HALAR e BELL 1994 e OLIVEIRA e col 1999).

\subsection{TUBERCULOSE E O REPOUSO}

Diante de tais efeitos adversos sobre o repouso, um grupo de pesquisadores australianos, da Universidade de Queensland (1999), realizaram uma revisão bibliográfica, através da Medline e Cochrane, sobre todas as citaçōes de repouso em trabalhos de experimentaçōes randomizadas, dos quais foram achados 39 experimentaçōes com referência ao repouso, sendo que em 15 circunstâncias diferentes, totalizando um número de 5777 pacientes analisados (ALLEN e col 2000).

Em 24 experimentações que investigam o repouso depois de algum procedimento médico, nenhum resultado apresentou melhora significativa e 8 pioraram significativamente após alguns procedimentos (punção lombar, anestesia espinhal, radiculografia e cateterismo cardíaco) (ALLEN e col 2000).

Em 15 experimentações que analisaram o repouso como um tratamento preliminar, nenhum resultado apresentou melhora significativa e 9 pioraram significativamente para algumas circunstâncias (lombalgia aguda, trabalho de parto, hipertensão proteinúrica durante a gravidez, infarto do miocárdio e hepatite 
infecciosa aguda). Ao revisar a literatura, os pesquisadores concluiram que 0 repouso é freqüentemente imposto pelos sintomas (principalmente a fraqueza) e que se deve distinguir o uso do repouso na vigência desses sintomas para o alívio ou de seu uso para apressar a recuperação (tratamento prescrito). Talvez o paciente seja o melhor juiz para quantificar a quantidade de repouso necessária (ALLEN e col 2000).

E terminam "O conselho dado em 1944, parece hoje curioso e apropriado: o médico deve sempre considerar o repouso absoluto como uma prescrição altamente antifisiológica e definitivamente perigosa na terapia, deve ser somente requisitado para indicações específicas e deve ser interrompido assim que possivel" (ALLEN e col 2000).

Diante de tais referências sobre os efeitos deletérios do repouso e voltando a tuberculose, o paciente com esta doença apresenta quadro clínico de perda de peso acentuada e caquexia, o que aumenta o risco deste desenvolver a síndrome do imobilismo, que associado à prescrição de repouso fatalmente leva o paciente a ter a síndrome instalada, levando muitos a invalidez temporária ou permanente, podendo ainda ser confundida como uma piora da doença e não como um efeito deletério do imobilismo.

NOGUEIRA (2001) analisou as internaçōes por tuberculose no Estado de São Paulo de 1984 a 1997 e constatou que: 
"A caquexia, foi entre os motivos clínicos, a que teve o maior aumento das anotaçőes nesses anos. Esse estado de desnutrição intensa está presente nas formas mais adiantadas da tuberculose, pois, como uma doença consumptiva, ela vai aos poucos levando o paciente a esse estado nutricional patológico. Um paciente em estado de caquexia é indicativo de que é um caso crônico, com algum tempo de doença e que não recebeu tratamento ou o tratamento não foi corretamente prescrito ou seguido."

Isto nos leva a pensar sobre quais seriam os motivos que levam a contra indicação da fisioterapia nestes pacientes hospitalizados, uma vez que estão recebendo a quimioterapia antituberculose.

Portanto, a proposta deste trabalho é verificar se pacientes com tuberculose, em regime hospitalar, sem tratamento fisioterapêutico, desenvolvem a sindrome do imobilismo. 


\section{OBJETIVOS}

\subsection{OBJETIVO GERAL}

Verificar se pacientes com tuberculose, em regime hospitalar, sem tratamento fisioterapêutico, desenvolvem a síndrome do imobilismo.

\subsection{OBJETIVOS ESPECIFICOS}

- Comparar avaliaçōes fisioterapêuticas realizadas em dois momentos, durante o período de internação, com intervalos de aproximadamente 1 mês em pacientes com tuberculose pulmonar internados em um Hospital de longa e outro de curta permanência.

- Comparar os grupos segundo as seguintes variáveis dependentes: índice de massa corpórea, deambulação, lombalgia, freqüência cardíaca, frequência respiratória, expansibilidade torácica, ausculta pulmonar, evacuações, diurese (sondas, catéteres, utensílios para urinar) escala análoga da dor, mapa corporal e neuropatia periférica. 


\section{METODOLOGIA}

\subsection{DELINEAMENTO DO ESTUDO}

Foi realizado um estudo transversal descritivo em um hospital de longa permanência (sanatórios) na cidade de Campos do Jordão e em outro hospital de curta permanência no municipio de São Paulo no período de junho de 2002 à fevereiro de 2003.

\subsection{POPULAÇÃO ESTUDADA E LOCAL DE ESTUDO}

A população estudada foi de 25 pacientes escolhidos aleatoriamente, internados em enfermarias de um hospital de longa e em enfermarias de outro hospital de curta permanência, com diagnóstico clínico ou laboratorial de tuberculose pulmonar (segundo a Classificação Internacional de Doenças - CID -10).

Os dados foram coletados pela própria pesquisadora somente aos sábados, o que propiciou o número pequeno da população. Outro fator que influenciou consideravelmente foi o fato da pesquisadora trabalhar no hospital de curta permanência, no qual funcionários do setor, assim como os pacientes que preenchiam os critérios de inclusão, confundiam a pesquisa com atendimento fisioterapêutico prejudicando 
a continuação das entrevistas. Aos sábados, também é maior o número de visitas de familiares nos dois hospitais analisados o que as vezes impedia a pesquisa. No hospital de longa permanência, os pacientes podem sair dos sanatórios e além disso estes precisam cumprir o horário de repouso obrigatório rígido de 1 hora durante o qual não podiam ser entrevistados.

Os critérios de inclusão foram pacientes de ambos os sexos e qualquer faixa etária, exceto crianças, que estivessem internados no hospital de longa ou curta permanência e que aceitassem participar da pesquisa, sendo feita uma avaliação fisioterapêutica em dois momentos durante sua internaçăo, com aproximadamente um mês de diferença entre elas, com o consentimento do paciente ou do responsável, que assinaram o termo de consentimento (ANEXO 1).

Foram excluidos do estudo, pacientes com diagnóstico não esclarecido, que apresentavam risco de vida ou que se recusaram a participar do estudo.

As direções do hospital de longa e de curta permanência foram contatadas para esclarecer os objetivos do trabalho e autorização da pesquisa.

O projeto foi aprovado pela Comissão de Pesquisa e Ética da Faculdade de Saúde Pública da USP, seguindo os requisitos da Resolução 196/96 do Conselho Nacional de Saúde / Ministério da Saúde do Brasil e as normas internas da Faculdade de Saúde Pública da USP, que regulamentam pesquisas envolvendo seres humanos. 


\subsection{INSTRUMENTO DE PESQUISA}

O instrumento de pesquisa foi um formulário de avaliação fisioterapêutica especificamente elaborado para 0 estudo, compreendendo avaliações através de palpações, mensurações através de aparelhos específicos e entrevistas com perguntas abertas e fechadas (LAKATOS e MARCONE 1995).

Antes do início do trabalho de campo, foi realizado um pré-teste no hospital de curta permanência na enfermaria de ortopedia e traumatologia em 3 indivíduos para padronização das tomadas das medidas.

As informações sobre os pacientes analisados foram obtidas mediante entrevistas individuais, aplicando-se um questionário (ANEXO 2).

A estrutura do formulário de avaliação foi elaborado com base em pesquisa na literatura e adaptada aos objetivos do presente estudo e após a aplicação de um pré-teste.

Foram realizadas duas avaliações durante o período de internação dos doentes pelo próprio pesquisador.

\subsection{VARIÁVEIS DE ESTUDO}

As variáveis dependentes do estudo foram as variáveis relacionadas com o exame físico do paciente que constam na Ficha de Avaliação 
Fisioterapêutica (ANEXO 2) e foram atribuídos valores numéricos para cada variável para elaboração de uma escala de graduação de imobilismo, na qual os resultados que estivessem mais próximos das alterações causadas pelo imobilismo receberam o maior valor numérico e vice-versa (ANEXO 3).

3.4.1. Variáveis Dependentes

\section{- Sistema Músculo-esquelético}

Peso (P): para estimativa do peso corporal foi utilizada balança eletrônica do tipo plataforma com capacidade para $150 \mathrm{~kg}$ e graduação em $100 \mathrm{~g}$ (PLENA modelo MEA-07400) com os pacientes trajando roupas leves e descalços.

Altura (Alt): foi mensurada utilizando fita métrica colocada na parede com escala em centímetros $(\mathrm{cm})$.

Cuidados ao se Efetuar as Medidas Longitudinais:

1. O indivíduo estava descalço;

2. O individuo mantinha-se em pé, com os pés juntos e voltados para frente, ombros relaxados e braços ao longo do corpo, rigorosamente posicionado;

3. Alguns autores recomendam, que o individuo faça inspiração, procurando compensar 0 achatamento dos discos intervertebrais, ocorridos durante o dia, o que foi ignorado pois todas as medidas foram feitas no periodo da manhā. 
Índice de Massa Corpórea (IMC): foi feito o cálculo a partir do peso e altura mensurados previamente, segundo fórmula:

\section{$I M C=$ Peso Altura $^{2}$}

No qual foram classificados da seguinte forma:

- Normal (IMC entre 18.5 e 24.9): valor numérico igual a 1

- Sobrepeso (IMC entre 25.0 e 29.9): valor numérico igual a 2

- Obesos (IMC entre 30.0 e 39.9): valor numérico igual a 3

- Obesos mórbidos (IMC acima de 40.0): valor numérico igual a 4

- Desnutridos (IMC abaixo de 18.5): valor numérico igual a 5

Deambulacão: foi solicitado ao paciente que deambulasse no corredor e após observação da marcha o paciente foi classificado como:

- Normal: o paciente que não apresentou alteração na marcha recebeu um valor numérico correspondente ao valor 1 .

- Auxílio para deambular: o paciente que necessitou de algum auxílio, seja por meio de muletas, bengalas, auxílio de outra pessoa ou apresentou alguma dificuldade para deambular recebeu valor numérico igual a 2 .

- Acamado: caso o paciente não apresentou marcha a mais de 24 horas ou fosse cadeirante recebeu um valor numérico correspondente ao valor 3 .

Lombalgia: variável estudada nestes indivíduos, uma vez que na literatura consultada, esta aparece como sendo um dos primeiros 
sintomas da síndrome do imobilismo, isto porque, ao permanecer por muito tempo em repouso, principalmente em decúbito dorsal, há um encurtamento da cadeia muscular posterior (musculatura antigravitacional) levando a um aumento excessivo da lordose lombar, o que pode acarretar em um pinçamento e consequentemente dor, mostrando relação direta com o imobilismo. Sendo assim, utilizando o mapa corporal e a escala análoga da dor, os pacientes desta população que apresentaram algum sintoma, principalmente dor, na região lombar foram considerados como tendo uma predisposição presente, para o imobilismo recebendo valor numérico igual a 2, caso não apresentassem nenhum sintoma, foram chamados de ausente e receberam valor numérico igual a 1 .

\section{> Sistema Cardiovascular}

Frequiência Cardíaca (Fc): O pulso foi mensurado pelo pesquisador na artéria braquial e contado através de um relógio comum de ponteiro, durante 30 segundos e multiplicado em seguida por 2 para se obter a quantidade de batimentos cardíacos que ocorreram em 60 segundos, onde cada item recebeu um valor numérico e foram classificados da seguinte forma: (IRWIN e TECKLIN 1994 e O'SULLIVAN e SCHMITZ 1993).

- Normocárdio: Fc entre 60 e 80 batimentos por minuto, cujo valor numérico corresponde ao número 1. 
- Bradicárdio: Fc abaixo de 59 batimentos por minuto o qual recebeu valor igual a 2 .

- Taquicárdio: Fc acima de 81 batimentos por minuto e recebeu valor 3 .

\section{> Sistema Respiratório}

Expansibilidade: o examinador colocou as duas mãos sobre o tórax do paciente, de forma que os polegares se encostassem e seguiu o movimento respiratório e classificou da seguinte forma (IRWIN e TECKLIN 1994; O'SULLIVAN e SCHMITZ 1993 e AZEREDO 1996):

- Diminuído: quando este apresentasse movimentos torácicos discretos, ou melhor, superficiais, o qual recebeu valor numérico igual a 2.

- Normal: quando o paciente apresentasse uma boa expansão de caixa torácica e recebeu valor igual a 1.

Ausculta Pulmonar (AP): confirma os achados da inspeção ou identifica regiōes com prejuízo da ventilação ou de eliminação de secreções. O examinador, com auxílio de um estetoscópio Litman, posicionou o paciente sentado (caso não fosse possível o paciente foi colocado em decúbito lateral), com o tórax do paciente exposto, o pesquisador começou a auscultar de forma simétrica através da linha grega, ou seja, face anterior: ápice direito - ápice esquerdo, terço médio direito - terço médio esquerdo, base direita - base esquerda e lateral direita - lateral esquerda; face posterior repetir a seqüencia 
acima (IRWIN e TECKLIN 1994; O'SULLIVAN e SCHMITZ 1993 e AZEREDO 1996). Foi avaliado o murmúrio vesicular (presente ou ausente e diminuído ou aumentado) e ruidos adventícios (roncos, sibilos e estertores crepitantes). Esta variável não foi classificada devido à dificuldade de mensuração.

Freqüência Respiratória (fr): As inspirações foram contadas durante 30 segundos sem o paciente perceber, e multiplicada por 2 para se obter o número de inspirações durante 1 minuto, no qual cada item recebeu um valor numérico, então foram assim classificados (IRWIN e TECKLIN 1994; O'SULLIVAN e SCHMITZ 1993 e AZEREDO 1996):

- Eupnéia: freqüência respiratória entre 12 e 20, recebendo valor numérico igual a 1.

- Bradipnéia: freqüência respiratória menor ou igual a 11, recebendo valor igual a 2 .

- Taquipnéia: freqüência respiratória maior ou igual a 21, recebendo valor igual a 3 .

\section{Sistema Gastrointestinal}

Evacuacð̋es: foi perguntado pelo examinador o hábito intestinal do paciente nos últimos 3 dias (72 horas) e foi classificado em:

- Normal: recebeu o valor numérico 1

- Diarréia: recebeu o valor numérico 2

- Constipação: recebeu valor numérico 3 


\section{Sistema Geniturinário}

Diurese: foi indagado pelo examinador sobre a freqüência da diurese, se o paciente apresentasse dor ao urinar e/ou utilizasse algum utensilio (exemplo: fraldas, papagaio, uripen, sondas etc...) foi classificado da seguinte forma:

× Freqüência

$\checkmark$ Duas vezes ou menos por dia: alterado

$\checkmark$ Mais de duas vezes por dia: normal

$\times$ Dor ao urinar

$\checkmark$ Presente

$\checkmark$ Ausente

$\times$ Utensílios para urinar

$\checkmark$ Presente

$\checkmark$ Ausente

Sendo assim o paciente foi classificado quanto ao sistema geniturinário da seguinte forma:

- Bom, quando urinava mais de duas vezes por dia, ausência de dor e ausência de utensílios, recebendo o valor numérico correspondendo a 1;

- Regular, quando apresentava uma resposta positiva e duas negativas, recebendo o valor igual a 2;

- Ruim, quando apresentava duas ou três respostas positivas o qual recebeu valor numérico igual 3. 


\section{Sistema Nervoso}

Escala Análoga da Dor e Mapa Corporal: foi perguntado ao paciente se este apresentava alguma dor, caso o paciente referisse dor foi apresentado à escala análoga da dor , com valores de 0 (zero) a 10 para que o mesmo a quantificasse e foi apresentado o mapa corporal para localizar o segmento envolvido, sendo assim classificados da seguinte forma (FIGURA 1):

- Sem dor: recebeu valor numérico igual a 0 (zero)

- Dor fraca (valores da escala de 1-3): valor numérico igual a 1.

- Dor moderada (valores da escala de 4-6): valor numérico igual a 2.

- Dor forte (valores da escala de 7-10): valor numérico igual a 3.

Caso o paciente apresentasse dor em mais de um segmento e com intensidades diferentes foi considerada sempre a dor de maior intensidade, para facilitar a análise. 
FIGURA 1: Escala Análoga de Dor e Mapa Corporal

Sem dor

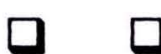

01 $\begin{array}{llll}2 & 3 & 4 & 5\end{array}$

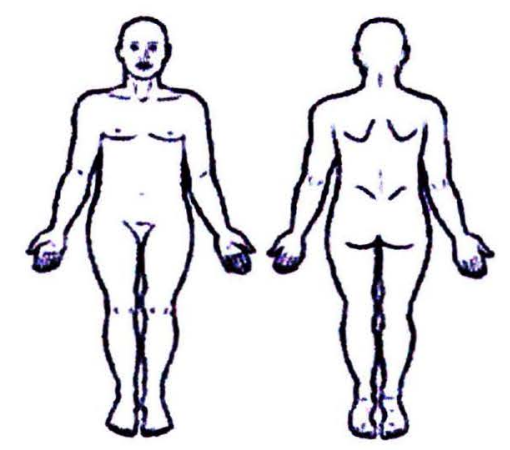

Muita dor

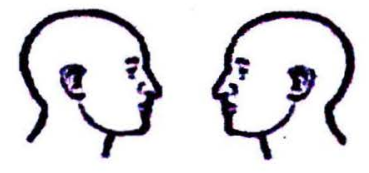

Fonte: Fisioterapia : Avaliação e Tratamento (O'SULLIVAN e SCHMITZ 1993)

Neuropatia periférica: usando a mesma escala análoga de dor e - mapa corporal, os indivíduos desta população que apresentaram algum sintoma de membro inferior, principalmente dor, parestesia (formigamento) e diminuição de sensibilidade foram classificados como sendo uma predisposição presente para neuropatia periférica, recebendo valor numérico igual a 2 e caso não apresentassem sintomas e sinais receberam valor numérico igual a 1.

Apesar da neuropatia periférica não fazer parte da síndrome do imobilismo, se fez necessário sua avaliação visto que a isoniazida, quimioterápico utilizado no tratamento para tuberculose pulmonar, apresentar algumas vezes, como efeito colateral esta doença. Outro fator considerável é que existe uma incidência alta de pacientes 
etilistas, somando portanto mais um fator de risco para o desenvolvimento da neuropatia periférica, a qual pode evoluir para uma deficiência proprioceptiva ou sensorial levando a anormalidades da marcha favorecendo desta forma o imobilismo.

\subsubsection{Caracterização dos Pacientes}

a) Estado civil: dividida em duas categorias: presença ou ausência de companheiro.

b) Idade do paciente: foi considerada a idade em anos completos, no momento da entrevista.

c) Sexo: masculino e feminino.

d) Escolaridade do paciente: referida pelo individuo por anos completos de estudo formal. Os indivíduos foram distribuídos em dois grupos: menor ou igual a 4 anos de estudo e superior a 4 anos de estudo.

e) Ocupação: refere-se aos indivíduos com trabalho remunerado, desempregado, aposentado ou que não trabalha fora (dona de casa), que foi classificado como nenhuma das anteriores (NDA).

f) Tipo de moradia: variável qualitativa dividida em três niveis: casa de alvenaria, casa mista e casa de madeira.

g) Hábitos nocivos: foram analisados três hábitos: tabagismo, etilismo e drogas através de questões abertas e fechadas. 
- Tabagismo: ( ) sim ( ) não - se sim a quantos anos e quantos maços fuma ? - se já fumou e parou, quando parou, por quantos anos fumou e quantos maços fumava?

- Etilismo: ( ) sim ( ) não - se sim a quantos anos bebe e qual a quantidade ? - se já bebeu e parou, há quanto tempo parou, por quantos anos bebeu e quanto bebia?

- Drogas: ( ) sim ( ) não - se sim qual tipo de droga que usa, a quanto tempo e qual a freqüência ? - se já usou e parou, qual droga usou, há quanto tempo parou e por quanto tempo usou ?

\subsection{ANÁLISE DOS DADOS}

Os dados obtidos neste estudo foram colocados em planilhas do EXCEL, programa da Microsoft Millenium.

Os resultados foram analisados através de porcentagem, média, mediana e variação, na qual a fórmula da variação foi a seguinte:

\section{Variação $=$ Pré - Pós}

Pré

Onde:

- Pré: é a primeira avaliação fisioterapêutica;

- Pós: é a segunda avaliação fisioterapêutica.

Foi elaborado um escore (ANEXO 3) para facilitar a análise onde foram classificados da seguinte forma: 
- Melhorou: este foi assim classificado quando na $2^{\mathrm{a}}$ avaliação fisioterapêutica apresentou melhores resultados que na $1^{\mathrm{a}}$, o qual recebeu valor numérico igual a 1.

- Manteve: quando este obteve os mesmos resultados em ambas as avaliações, recebendo valor numérico igual a $2^{\text {a }}$.

- Piorou: quando na $2^{\mathrm{a}}$ avaliação fisioterapêutica apresentou piores resultados que na $1^{\mathrm{a}}$, o qual recebeu valor numérico igual a 3.

Após ter sido feita esta análise individual de sistema por sistema, foi feita a soma de todos os sistemas analisados de cada indivíduo e feita novamente a variação.

Sendo assim foi elaborado uma Escala de Graduação de Imobilismo:

- Normal: valores de $10-14$

- Leve: valores de $15-19$

- Moderado: valores de 20-24

- Grave: valores de 25 ou + 


\section{RESULTADOS E DISCUSSÃO}

A população estudada correspondeu a $6(24 \%)$ indivíduos do sexo feminino e 19 (76\%) do sexo masculino, totalizando 25 indivíduos. Em relação às características desta população foi possivel observar que a idade média era de 47 anos de idade, $80 \%$ moravam em casas de alvenaria, com tempo médio de internação de 133,16 dias (mediana de 88 dias), $36 \%$ estavam desempregados e $36 \%$ apresentavam algum trabalho remunerado.

Estas características se assemelham as encontradas em outros trabalhos, como por exemplo em relação as ocupações, onde GALESI, 1998, que analisou a mortalidade por tuberculose no município de São Paulo de 1986 a 1995 constatou que 23\% da ocupação era ignorada, justificado pela autora pela dificuldade de se estabelecer categorias e classificações ocupacionais.

Em relação a renda, nesta população, $52 \%$ não apresentavam nenhum tipo de renda, $56 \%$ baixo grau de escolaridade e $72 \%$ não tinham companheiro, o que dificulta a adesão a qualquer tipo de tratamento.

A incidência da tuberculose, mundialmente, ocorre em uma faixa etária considerada produtiva, apresentando um grande impacto econômico, assim como encontrado neste estudo, no qual $80 \%$ dos casos encontram-se na faixa de 30 a 59 anos. 
Quanto aos hábitos nocivos, $76 \%$ destes indivíduos bebiam, sendo que $68 \%$ afirmaram ter parado de beber no momento da internação. Em relação ao tabagismo, $84 \%$ destes indivíduos referiram fumar, inclusive durante o período de internação e somente 6 , que corresponde a $24 \%$ destes indivíduos parou de fumar no ato da internação. Quanto a drogas, somente 1 paciente refere ter experimentado maconha e usado durante 1 ano.

Outra pergunta feita a estes pacientes foi se era a primeira vez que apresentavam tuberculose, o resultado obtido foi que 6 indivíduos apresentavam pela segunda vez a tuberculose, ou seja, $24 \%$ da população (GRÁFICO 1).

GRÁFICO 1: Distribuição percentual de casos novos e reicidivas em indivíduos com tuberculose pulmonar internados em um hospital de curta e outro de longa permanência, Estado de São Paulo, de junho de 2002 e fevereiro de 2003.

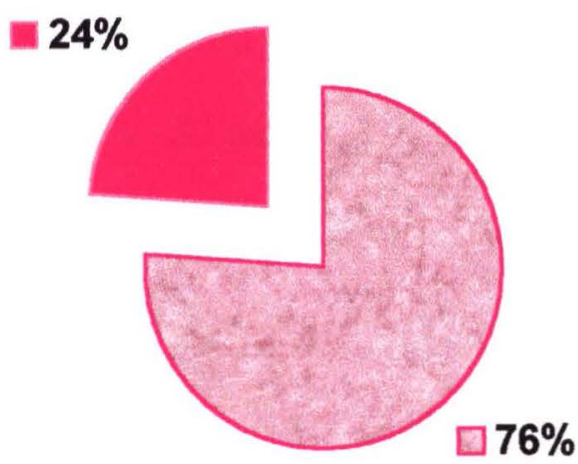


Destes 6 individuos, somente 2 não terminaram o esquema de tratamento anterior e referiram que não terminaram devido a dependência do álcool, sendo que 5 destes indivíduos apresentaram pela segunda vez o quadro de tuberculose em um periodo inferior há 5 anos, o que poderia ser considerado, portanto, como um retratamento da doença. LERNER, 1996, relata o uso abusivo do álcool em sanatórios, como sendo um problema de saúde pública muito antigo e que hoje vivemos novas realidades, como por exemplo a AIDS, portanto, condutas e normas devem ser revistas para que não se cometam os mesmos erros do passado "segregação destes indivíduos".

Quanto ao tempo de internação foi possivel verificar que $48 \%$ dos indivíduos estavam internados a mais de 91 dias, sendo considerada uma internação de longa duração como pode ser observado na TABELA 1, sendo que $12 \%$ encontravam-se internados há mais de 181 dias, o que provavelmente significa falência de tratamento, uma vez que o tempo médio de tratamento preconizado pelo Ministério da Saúde é de 180 dias. 
TABELA 1: Distribuição do tempo de internação de indivíduos com tuberculose pulmonar, Estado de São Paulo, de junho de 2002 e fevereiro de 2003.

\begin{tabular}{ccc}
\hline TEMPO DE INTERNAÇÃO & N & $\%$ \\
\hline $0-30$ & 6 & $24 \%$ \\
$31-60$ & 3 & $12 \%$ \\
$61-90$ & 4 & $16 \%$ \\
$91-120$ & 1 & $4 \%$ \\
$121-150$ & 2 & $8 \%$ \\
$151-180$ & 6 & $24 \%$ \\
$181-220$ & 0 & - \\
$221-250$ & 1 & $4 \%$ \\
251 e + & 2 & $8 \%$ \\
\hline TOTAL & 25 & $100 \%$ \\
\hline
\end{tabular}

Sendo assim, feita a caracterização dos pacientes, foram analisadas as variáveis de acordo com os seguintes sistemas: músculo-esquelético, cardíaco, respiratório, gastrointestinal, geniturinário e nervoso.

O primeiro sistema avaliado foi o músculo-esquelético no qual foram analisados: IMC, deambulação e lombalgia.

A idéia inicial era avaliar e analisar trofismo, grau de força muscular e amplitude de movimento. Quanto a estas duas últimas medidas não foi possivel por falta de material específico, como dinâmometro e flexímetro. Já o trofismo, medida fundamental para este trabalho, foi analisado através de perimetria, no entanto a análise desta medida foi considerada subjetiva, uma vez que não existe nenhum 
parâmetro de normalidade e devido a maioria destes dados terem sido colhidos em Campos do Jordão, cidade com uma temperatura muito baixa, o que dificultava a avaliação, pois os pacientes não conseguiam ficar sem roupa por causa do frio, sendo assim esta medida foi descartada.

Segundo SARAIVA (1996), a diminuição do trofismo chamado por ele de amiotrofia, se torna evidente na segunda e terceira semana de repouso absoluto, onde o peso do músculo baixa de $20 \%$ pelo sétimo dia e $30 \%$ por volta do trigésimo dia.

BOOTH, 1982, observou um decréscimo na síntese de proteína em músculos imobilizados após a sexta hora de imobilização, o que ele atribuiu a causa da diminuição do trofismo.

Em relação ao IMC foi encontrado um grande número de pacientes desnutridos, tanto na primeira avaliação como na segunda avaliação correspondendo à $40 \%$ dos indivíduos, como é possivel observar na TABELA 2 .

TABELA 2: Correlação do Indice de Massa Corpórea entre a $1^{a}$ e a $2^{a}$ avaliação em indivíduos com tuberculose pulmonar internados, Estado de São Paulo, de junho de 2002 e fevereiro de 2003.

\begin{tabular}{cccc}
\hline $1^{0}$ Aval & Normal & Desnutrido & TOTAL \\
\hline Normal & 14 & 1 & 15 \\
Desnutrido & 1 & 9 & 10 \\
\hline TOTAL & 15 & 10 & 25 \\
\hline
\end{tabular}


Quando feita a variação entre a primeira e a segunda avaliação foi observado que 23 dos indivíduos que mantiveram-se na mesma faixa, $36 \%$ (9) apresentavam IMC abaixo do normal, ou seja, desnutridos. (GRAFICO 2)

GRÁFICO 2: Variação dos resultados, em porcentagem, do Indice de Massa Corpórea obtidos na primeira e segunda avaliação fisioterapêutica de indivíduos com tuberculose pulmonar internados, Estado de São Paulo, de junho de 2002 e fevereiro de 2003.

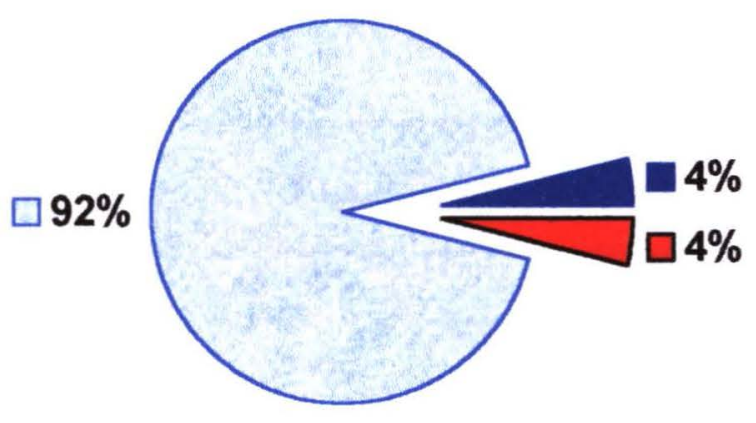

$\square$ MELHOROU (1) $\square$ MANTEVE (2) $\square$ PIOROU (3)

Segundo NOGUEIRA (2001), o mau estado geral e a caquexia são grandes responsáveis pelas causas de internação por tuberculose e com uma mortalidade elevada, como foi possível observar neste trabalho, onde $40 \%$ dos indivíduos encontravam-se desnutridos.

Importante salientar que tanto a tuberculose quanto o imobilismo levam a uma diminuição do trofismo, portanto fica difícil saber o que aconteceu primeiro, contudo sabe-se que um indivíduo desnutrido se sente fraco e que a fraqueza perpetua o repouso. 
Em relação a deambulação, foi observado que tanto na primeira como na segunda avaliação, $44 \%$ dos indivíduos estudados apresentavam algum déficit de marcha, necessitando de algum auxilio, e quando feita a variação, $32 \%$ mantiveram com algum tipo de déficit na marcha e $8 \%$ pioraram (TABELA 3). Este déficit na marcha favorece o imobilismo.

TABELA 3: Correlação dos resultados da Deambulação obtidos na primeira e segunda avaliação fisioterapêutica de indivíduos com tuberculose pulmonar internados, Estado de São Paulo, de junho de 2002 e fevereiro de 2003.

\begin{tabular}{ccccc}
\hline $2^{\circ}$ Aval & Normal & Auxilio & Acamado & TOTAL \\
\hline Normal & 12 & 2 & 0 & 14 \\
Auxilio & 1 & 7 & 0 & $\mathbf{8}$ \\
Acamado & 0 & 1 & 2 & 3 \\
\hline TOTAL & $\mathbf{1 3}$ & $\mathbf{1 0}$ & $\mathbf{2}$ & $\mathbf{2 5}$ \\
\hline
\end{tabular}

Outra variável estudada nestes indivíduos foi a lombalgia, na qual 7 indivíduos desta população (28\%) apresentaram algum sintoma relacionado a lombalgia. Destes indivíduos, $16 \%$ apresentaram melhora na segunda avaliação e $8 \%$ pioram (TABELA 4). Para esta variável não foi feito nenhum teste específico e foi considerado simplesmente o paciente ter apresentado dor lombar, identificado pelo paciente no mapa corporal. No entanto, esta é uma variável que deve ser considerada, pois muitas vezes pode ser um dos primeiros sinais de imobilismo, isto porque, ao permanecer por muito tempo em 
repouso, principalmente em decúbito dorsal, há um encurtamento da cadeia muscular posterior (musculatura anti-gravitacional) levando a um aumento excessivo da lordose lombar, o que pode acarretar em um pinçamento e consequentemente dor, mostrando relação direta com o imobilismo.

TABELA 4: Correlação dos sintomas de Lombalgia obtidos na primeira e segunda avaliação fisioterapêutica de indivíduos com tuberculose pulmonar internados, Estado de São Paulo, de junho de 2002 e fevereiro de 2003.

\begin{tabular}{|c|c|c|c|}
\hline $1^{0}$ Aval ${ }^{0}$ Aval & Ausente & Presente & TOTAL \\
\hline Ausente & 18 & 2 & 20 \\
\hline Presente & 4 & 1 & 5 \\
\hline TOTAL & 22 & 3 & 25 \\
\hline
\end{tabular}

No sistema cardiovascular a única variável possivel de estudar foi a frequência cardiaca. A princípio havia sido idealizado o teste incremental de 6 minutos incentivado, que talvez trouxesse uma análise mais objetiva, no entanto, não foi possivel realizar, devido ser um teste relativamente demorado e por haver pacientes acamados que estariam impossibilitados de realizar o teste, podendo influenciar na análise. Sendo assim, foram feitas mensuraçōes da frequência cardíaca tanto na primeira avaliação como na segunda, o que evidenciou que a maioria dos pacientes apresentavam taquicardia (48\% e $64 \%)$, o que pode sugerir um descondicionamento cardiovascular (TABELA 5). 
TABELA 5: Correlação da Frequência Cardíaca obtidos na primeira e segunda avaliação fisioterapêutica de indivíduos com tuberculose pulmonar internados, Estado de São Paulo, de junho de 2002 e fevereiro de 2003.

\begin{tabular}{ccccc}
\hline $\mathbf{1}^{0}$ Aval & Normo & Bradi & Taqui & TOTAL \\
\hline Normocárdico & 7 & 0 & 6 & 13 \\
Bradicárdico & 0 & 0 & 0 & 0 \\
Taquicárdico & 2 & 0 & 10 & 12 \\
\hline TOTAL & 9 & 0 & 16 & 25 \\
\hline
\end{tabular}

Quando feita a variação, observou-se que dos 19 pacientes que se mantiveram na mesma faixa, $44 \%$ (11) destes mantiveram-se taquicárdicos.

RAPOSO e LOPEZ, 2002, dizem que com o imobilismo ocorre um comprometimento no desempenho cardiovascular, ocasionando um aumento da frequência cardíaca de repouso, onde o pulso aumenta um batimento por minuto a cada 2 dias. Após três semanas são necessárias de 26 a 72 dias de atividades contínuas para retornar o nível prévio ao repouso, o qual corresponde a uma redução de $25 \%$ do desempenho cardiovascular. A hipotensão ortostática e a taquicardia podem resultar como tentativas do coração compensar a queda deste volume, que é dado segundo OLIVEIRA e col (1999) e ROWLAND (2000) por uma elevação da pressão arterial sistólica pelo aumento da resistência periférica, e o tempo de ejeção sistólico absoluto e da diástole é encurtado, diminuindo o volume sistólico. 
DEITRICK e col, 1948, ao estudar 4 indivíduos saudáveis submetidos ao repouso absoluto observou que houve uma diminuição no volume sanguíneo total em média de $5.4 \%$, uma diminuiçäo a tolerância ao exercício e aumento da freqüência cardíaca.

Outro sistema avaliado, nestes indivíduos, foi o sistema respiratório, no qual foram avaliados a frequência respiratória e a expansibilidade. Vale lembrar que os indivíduos estudados apresentavam tuberculose pulmonar, sendo assim, os resultados aqui interpretados podem ter sofrido influência tanto da doença quanto por conta do imobilismo.

Nos indivíduos desta população a grande maioria apresentou taquipnéia, $60 \%$ e $76 \%$ respectivamente (TABELA 6), sendo que $64 \%$ mantiveram-se na mesma faixa quando analisados conjuntamente e destes, 52\% mantiveram-se taquipnéicos, correspondendo a mais da metade dos indivíduos analisados que somados aos $28 \%$ (7) que pioraram, totaliza $80 \%$ de indivíduos taquipnéicos nesta população.

TABELA 6: Correlação da Frequência Respiratória obtidos na primeira e segunda avaliação fisioterapêutica de indivíduos com tuberculose pulmonar internados, Estado de São Paulo, de junho de 2002 e fevereiro de 2003.

\begin{tabular}{ccccc}
\hline 10 Aval $^{0}$ Aval & Eupnéico & Bradipnéico & Taquipnéico & TOTAL \\
\hline Eupnéico & 3 & 1 & 5 & 9 \\
Bradipnéico & 0 & 0 & 1 & 1 \\
Taquipnéico & 2 & 0 & 13 & 15 \\
\hline TOTAL & 5 & 1 & 19 & 25 \\
\hline
\end{tabular}


Já em relação a expansibilidade foi observado que a maioria também apresentava-se diminuida, $68 \%$ na primeira avaliaçäo e $40 \%$ na segunda avaliação. Na variação 13 (52\%) mantiveram-se com expansibilidade diminuida e $2(8 \%)$ pioraram o que soma $60 \%$ com expansibilidade diminuída na segunda avaliação.

TABELA 7: Variação dos resultados da avaliação da Frequência Respiratória obtidos na primeira e segunda avaliação fisioterapêutica de individuos com tuberculose pulmonar internados, Estado de São Paulo, de junho de 2002 e fevereiro de 2003.

\begin{tabular}{lcc}
\hline VARIAÇÃO & N & $\%$ \\
\hline MELHOROU (1) & 2 & $8 \%$ \\
MANTEVE (2) & 16 & $64 \%$ \\
PIOROU (3) & 7 & $28 \%$ \\
\hline TOTAL & $\mathbf{2 5}$ & $\mathbf{1 0 0 \%}$ \\
\hline
\end{tabular}

Em relação ao sistema respiratório, HALAR e BELL (1994) dizem ser o local de complicações ameaçadoras da vida durante a imobilidade prolongada, levando a uma diminuição de volumes e capacidades pulmonares em torno de 25 a $50 \%$. Os músculos respiratórios debilitados podem impedir a expansão da parede torácica e desta forma dificultar a troca gasosa adequada e consequentemente um déficit do mecanismo de tosse e do movimento ciliar o que favorece um terreno propicio para infecções (OLIVEIRA e col 1999).

Em resumo, embora as variáveis estudadas no sistema respiratório sejam consideradas subjetivas, esta respiração superficial, 
independente da causa, pela doença ou pelo imobilismo, pode levar a sérios prejuízos para estes individuos, devendo ser um fator de atenção para os profissionais da saúde devido ao risco de atelectasias e até mesmo de uma acidose respiratória que pode evoluir para uma falência respiratória ou cardiaca e muitas vezes à morte.

No sistema gastrointestinal foi analisado a variável relacionada com a evacuação, que talvez tenha sofrido viés devido a pesquisadora ser mulher e a maioria dos indivíduos desta população serem do sexo masculino $(76 \%)$, onde muitas vezes antes de terminar a pergunta, 0 indivíduo se antecipava e respondia, e mesmo com insistência da pergunta era observado um certo constrangimento na hora da resposta.

Mesmo assim, na primeira avaliação, 20\% apresentaram constipação e $8 \%$ na segunda avaliação, quando feita a variação somente $1(4 \%)$ indivíduo se manteve constipado e 1 (4\%) piorou, somando portanto $8 \%$ de constipação na segunda avaliação (TABELA 8). Isto é comumente observado no individuo em repouso prolongado principalmente pelo aumento da inibição adrenérgica, diminuindo o peristaltismo e provocando a contração esficteriana, agravada pela baixa ingesta de líquidos, evoluindo muitas vezes para o fecaloma e, consequentemente cirurgia, agravando ainda mais o quadro inicial (BONNER 1969; DEITRICK 1948; HALAR e BELL 1994; OLIVEIRA e col 1999). 
TABELA 8: Correlação do Hábito Intestinal obtidos na primeira e segunda avaliação fisioterapêutica de indivíduos com tuberculose pulmonar internados, Estado de São Paulo, de junho de 2002 e fevereiro de 2003.

\begin{tabular}{ccccc}
\hline $\mathbf{1}^{0}$ Aval $^{0}$ Aval & Normal & Diarréia & Constipação & TOTAL \\
\hline Normal & 17 & 0 & 1 & $\mathbf{1 8}$ \\
Diarréia & 2 & 0 & 0 & $\mathbf{2}$ \\
Constipação & 4 & 0 & 1 & $\mathbf{5}$ \\
\hline TOTAL & $\mathbf{2 3}$ & $\mathbf{0}$ & $\mathbf{2}$ & $\mathbf{2 5}$ \\
\hline
\end{tabular}

No sistema geniturinário, $92 \%$ dos indivíduos analisados apresentaram-se sem mudanças quanto a frequência, dor ou uso de utensilios para urinar (como fraldas, papagaios, sondas e etc...). Exceto 4 individuos, que correspondem a $16 \%$ desta população mantiveram-se regular por conta do uso do papagaio, o que favoreceria o repouso, podendo ser considerado como uma predisposição para o imobilismo, além do que indivíduos que permanecem por muito tempo em repouso podem desenvolver uma disfunção urinária, isto porque, em decúbito dorsal, ocorre uma estase urinária que juntamente com aumento da excreção urinária de cálcio pode resultar em cólicas renais e infecções do trato urinário (BONNER 1969; DEITRICK 1948; HALAR e BELL 1994; OLIVEIRA e col 1999).

Em relação ao sistema nervoso ainda são poucos os estudos que mostram a relação existente entre 0 repouso prolongado e possiveis alterações neste sistema (SARAIVA 1996). O efeito da privação sensorial é um pouco mais conhecido e pode levar várias 
alterações como: ansiedade, depressão, insônia, agitação, irritabilidade, desorientação temporoespacial, diminuição da concentração, incoordenação e como avaliado nesta população a diminuição da tolerância a dor, através do mapa corporal e escala análoga da dor. A TABELA 9 , mostra que $72 \%$ destes indivíduos na primeira avaliação apresentaram algum tipo de dor e $66 \%$ na segunda avaliação, sendo que $11(44 \%)$ mantiveram-se na mesma faixa, porém dos que se mantiveram, 7 destes indivíduos permaneceram com dor, exceto 1, melhorou a intensidade da dor e 7 indivíduos (28\%) apresentaram piora em relação a intensidade da dor, dando um total de $56 \%$ de indivíduos com dor.

TABELA 9: Correlação da Intensidade de Dor obtidos na primeira e segunda avaliação fisioterapêutica de indivíduos com tuberculose pulmonar internados, Estado de São Paulo, de junho de 2002 e fevereiro de 2003.

\begin{tabular}{cccccc}
\hline $\mathbf{1}^{0}$ Aval $^{\mathbf{2}}$ Aval & Sem Dor & Fraca & Moderada & Forte & TOTAL \\
\hline Sem Dor & 4 & 1 & 1 & 1 & $\mathbf{7}$ \\
Fraca & 2 & 0 & 2 & 1 & $\mathbf{5}$ \\
Moderada & 3 & 0 & 1 & 1 & $\mathbf{5}$ \\
Forte & 1 & 0 & 1 & 6 & $\mathbf{8}$ \\
\hline TOTAL & $\mathbf{1 0}$ & $\mathbf{1}$ & $\mathbf{5}$ & $\mathbf{9}$ & $\mathbf{2 5}$ \\
\hline
\end{tabular}

Um outro item avaliado nestes individuos foi a neuropatia periférica, que apesar de não terem sido feito testes específicos, foram analisados através do mapa corporal, os pacientes que apresentaram algum sintoma em membros inferiores tais como: dor, parestesia 
(formigamento) e diminuição de sensibilidade foram classificados como sintomas presentes para neuropatia periférica. Isto porque a quimioterapia utilizada no tratamento para tuberculose apresenta como efeito colateral a neuropatia periférica e que associado ainda o fato de muitos destes pacientes fazerem uso de bebida alcóolica, $76 \%$, esta poderia ser uma variável de risco para o imobilismo uma vez que tais manifestações levariam a alterações de marcha favorecendo o repouso. Sendo assim, $8(32 \%)$ indivíduos apresentaram algum sinal de neuropatia periférica e quando feita a variação 5 indivíduos (20\%), desta população mantiveram-se com sinais de neuropatia periférica e 3 (12\%) pioraram somando um total de $32 \%$ (TABELA 10).

TABELA 10: Correlação dos resultados da avaliação de sinais de Neuropatia Periférica obtidos na primeira e segunda avaliação fisioterapêutica de indivíduos com tuberculose pulmonar, Estado de São Paulo, de junho de 2002 e fevereiro de 2003.

\begin{tabular}{cccc}
\hline $1^{0}$ Aval & Ausente & Presente & TOTAL \\
\hline Ausente & 14 & 3 & 17 \\
Presente & 3 & 5 & 8 \\
\hline TOTAL & 17 & 8 & 25 \\
\hline
\end{tabular}

Os tratamentos propostos para tuberculose somam, segundo ROSEMBERG (1999), quase 3 milênios, no entanto, o tratamento proposto até a chegada dos quimioterápicos por volta de 1940 , foi o regime higienodietético em sanatórios que segundo GALESI (1998) era uma forma de segregar e não tratar. 
Em contrapartida, BONNER (1969) diz:

"A tuberculose é outra entidade de doença que no passar dos anos foi tratada com repouso rigido. Com o advento da quimioterapia não só o exercício moderado mas atualmente a atividade normal é recomendada na maioria dos casos."

Ou como diz WIER e col (1961) apud MEAD e VALLEJO (1962) ele advoga não só a atividade física mas o exercício árduo para pacientes com tuberculose ativa que estejam recebendo a quimioterapia.

Por outro lado, apesar de hoje o tratamento para tuberculose ser ambulatorial em quase sua totalidade e algumas vezes supervisionado Directly observed treatment short chemotherapy - DOTS, ainda ocorrem internações, principalmente por fatores sociais (moradores de rua, alcóolatras, etc...), por intolerância ao tratamento, por gravidade da doença e para elucidação diagnóstica.

No período de julho de 2003, foram registradas 1272 internações em todo Brasil por tuberculose pulmonar e com tempo médio de internação de 28,2 dias (Ministério da Saúde - Sistema de Informações Hospitalares do SUS).

Muitas vezes, nestas internações, seja em hospitais, seja em sanatórios, o repouso ainda é empregado como forma de tratamento, apesar de não se ter nenhuma justificativa científica convincente.

A fisioterapia aparece na literatura como uma contra-indicação por risco de disseminação broncogênica, apesar de neste trabalho não ter sido encontrado nenhuma referência a este respeito, exceto 
CAVALCANTI (1935) que diz "o tuberculoso que não faz repouso direito raramente se cura". Vale lembrar que tal afirmação ocorreu antes do surgimento dos quimioterápicos.

Este dogma do repouso, segundo NAHUM apud BONNER (1969) "o repouso é um dogma fundado em nenhuma prova experimental e se perpetuou como todos os outros dogmas, por convicção. Seus sucessos foram interpretados falsamente, seus fracassos nem mesmo foram explicados e sua perpetuação verdadeiramente são um resultado de falta de conhecimento e inércia contra mudança".

Fato este comprovado através da observação clínica em sanatórios que ainda hoje, século XXI, estipulam horários rígidos de repouso, sujeitos inclusive a punições caso este seja descumprido.

Em hospitais gerais, o que na verdade acontece é que estes pacientes são colocados em isolamento respiratório, mesmo após a fase bacilifera, o que favorece o imobilismo isto quando não é colocado em prescrição repouso absoluto.

Diante disto, foi possivel observar que $52 \%$ pioraram e $8 \%$ (2) mantiveram-se com grau leve de imobilismo (GRÁFICO 3). Quando feita a variação final de cada indivíduo, incluindo todos os sistemas, o sistema que obteve maior variação negativa $(-0.16)$ foi o sistema cardiovascular e o que obteve maior variação positiva $(+0.21)$ foi o sistema gastrointestinal. 
GRÁFICO 3: Variação final dos resultados de todos os sistemas envolvidos na primeira e segunda avaliação fisioterapêutica de indivíduos com tuberculose pulmonar internados, do Estado de São Paulo, no período de junho de 2002 e fevereiro de 2003.

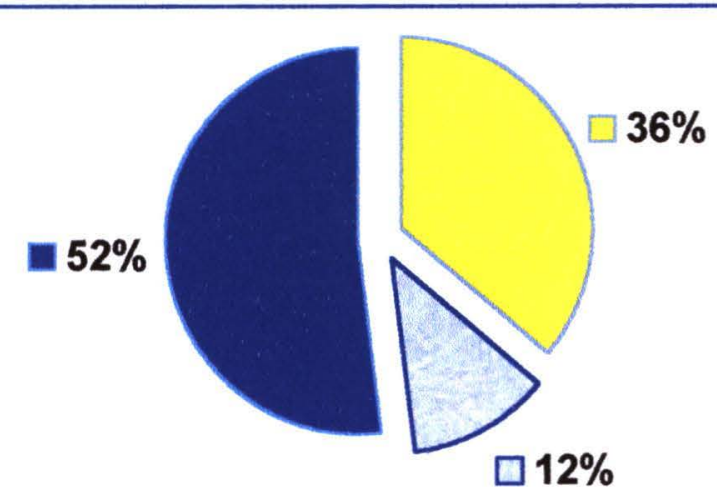

MELHOROU (1) $\square$ MANTEVE (2) $\mathbf{m}$ PIOROU (3)

Quanto a escala de imobilismo proposta neste trabalho foi possivel diagnosticar que na primeira avaliação $18(72 \%)$ dos indivíduos apresentavam algum grau de imobilismo e 16 (64\%) na segunda avaliação, como pode ser observado na TABELA 12.

TABELA 11: Distribuição do grau de severidade segundo a escala de imobilismo de individuos com tuberculose pulmonar internados, Estado de São Paulo, de junho de 2002 e fevereiro de 2003.

\begin{tabular}{lccccc}
\hline MOBILISMO & GRAU & PRE & $\%$ & POS & $\%$ \\
\hline Normal & $10-14$ & 7 & $28 \%$ & 9 & $36 \%$ \\
Leve & $15-19$ & 13 & $52 \%$ & 10 & $40 \%$ \\
Moderado & $20-24$ & 4 & $16 \%$ & 5 & $20 \%$ \\
Grave & 25 ou + & 1 & $4 \%$ & 1 & $4 \%$ \\
\hline TOTAL & -- & 25 & $100 \%$ & 25 & $100 \%$ \\
\hline
\end{tabular}


GRÁFICO 4: Distribuição do grau de severidade segundo a escala de imobilismo de indivíduos com tuberculose pulmonar internados, Estado de São Paulo, de junho de 2002 e fevereiro de 2003.

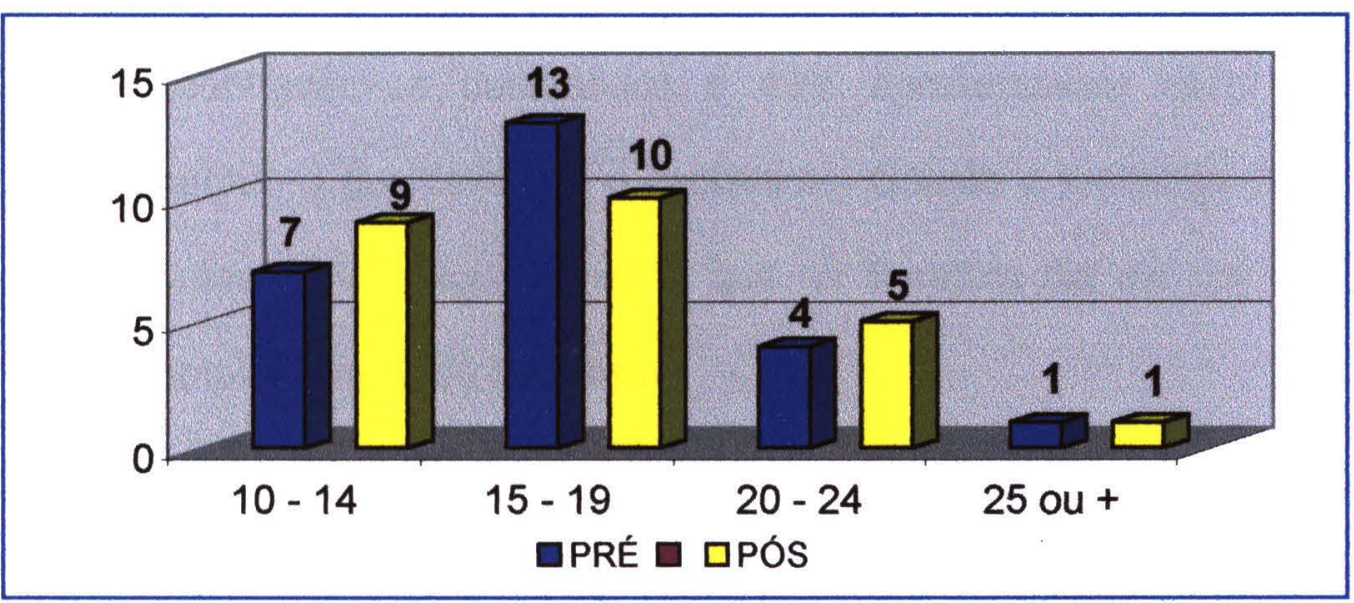

Finalizando, trabalhos como de DEITRICK e col (1948), realizado em indivíduos normais, mostraram as diversas alterações fisiológicas que acontecem em vários sistemas devido ao repouso prolongado e isto nos faz refletir até que ponto o tratamento através do repouso pode ser considerado benéfico e não deve ser reconsiderado, como diz ALLEN e col (2000) "o médico deve considerar o repouso absoluto como uma prescrição altamente antifisiológica e definitivamente perigosa na terapia, devendo ser somente requisitado para indicaçōes específicas e ser interrompido assim que possivel". 


\section{CONCLUSŐES}

- No sistema músculo-esquelético $40 \%$ dos indivíduos encontravam-se desnutridos e $40 \%$ apresentavam défict de marcha, o que favorece o imobilismo. Quanto a lombalgia $28 \%$ apresentavam algum sinal, o que na literatura diz ser um dos primeiros sinais do imobilismo.

- No sistema cardiovascular $44 \%$ encontravam-se taquicárdicos.

- No sistema respiratório $52 \%$ dos individuos mantiveram-se taquipnéicos e $28 \%$ pioraram, totalizando $80 \%$. Quanto a expansibilidade $60 \%$ apresentava-se diminuída. Estas variáveis podem sugerir uma acidose respiratória que pode evoluir para uma falência respiratória ou cardiaca e muitas vezes à morte.

- Sistema gastrointestinal $8 \%$ apresentaram quadro de constipação.

- Sistema nervoso $56 \%$ dos indivíduos apresentaram quadro de dor e $32 \%$ sinais de neuropatia periférica que sugere alterações na marcha favorecendo o repouso, no qual tal doença, apesar de não ter relação direta com o imobilismo, pode estar presente nestes individuos por causa da isoniazida e consumo de bebida alcóolica.

- Na variação dos sistemas observou-se que no sistema gastrointestinal houve a maior variação positiva $(+0.21)$ no entanto é o sistema que pode ter sofrido algum vies devido ao 
constrangimento dos entrevistados, enquanto no sistema cardiovascular houve a maior variação negativa $(-0.16)$, sugerindo um descondicionamento cardiovascular, que segundo a literatura pode levar até 72 dias para recuperação.

- Observou-se que $52 \%$ dos indivíduos analisados apresentaram algum grau de imobilismo, o que sugere que o repouso adotado como prática terapêutica é prejudicial nesta população, devendo portanto revisão desta conduta. 


\section{REFERENCIAS BIBLIOGRÁFICAS}

1. Abel EK. Taking the cure to the poor: patients' responses to New York City's tuberculosis program, 1894 to 1918. American Journal of Public Health; vol 87, pp 1808-1815: Washington; nov 1997.

2. Allen C, Glaszion P, Del'man, C. Bed rest : a potentially harmful treatment needing more careful evaluation. The Lancet, London; may 2000.

3. Azeredo CAC. Fisioterapia respiratória moderna. $2^{a}$ Edição. Brasil (São Paulo): Manole; 1996.

4. Bloomfield SA. Changes in musculoskeletal structure and function with prolonged bed rest. Medicine and Science in Sports and Exercise; 197-205; 1995.

5. Bonner $C D$. Rehabilitation instead of bed rest ? Geriatrics; June 1969.

6. Booth FW. Effect of limb immobilization on skeletal muscle. Journal of Applied Physiology Respiratory, Environmental and Exercise Physiology ; vol 52, n 5; May 1982. 
7. Buskirk ER. Pespectives on exercise and wasting. The Jornal of Nutrition; vol 129, pp S295-S302, Bethesda; Jan 1999.

8. Carr EK, Kenney FD. Positioning of the stoke patient: a review of the literature. International Journal of Nursing Studier; vol 29, $n^{\circ} 4$, pp 355-369; 1992.

9. Cavalcanti A. Como evitar e curar a tuberculose. Belo Horizonte, 1935.

10. Convertino VA, Bloomfield SA, Greenleaf JE. An overview of the issues: physiological effects of bed rest and restricted physical activity. Medicine and Science in Sports and Exercise; vol 29, $\mathrm{n}^{\circ} 2$, pp 87-190; 1997.

11. Cress RH, Burrel F, Fleming WC. A review of the dangers of prolonged bed rest. Ala. J. Med. Sci.; vol. 5, n 4; 1968.

12. Deitrick JE, Whedon DG, Shorr S. Effects of immobilization upon various metabolic and physiologic functions of normal men. Amer. J. Med. 4:3; 1948.

13. Delisa JA e col. Medicina De Reabilitação - Princípios E Prática. 1a Edição. Brasil (São Paulo): Manole; 1992. vol 2, pp 519535. 
14. D'epiro NW. Resurgent tb: stopping the spread. patient care; vol 31, pp 97-118, Oradell; May 1997.

15. Desbiens NA e col. Stress in caregivers of hospitalized oldest-old patients. The Jornals of Gerontology; vol 56a, pp M231, Washington; Apr 2001.

16. Dubos Rn, Dubos J. The white plague - tuberculosis, man, and society. Rutgers University Press, New Brunswick, New Jersey; 1992.

17. Fairchild AL, Oppenheimer GM. Public health nihilism vs pragmatism: history, politics, and the control tuberculosis. American Journal of Public Health; vol 88, pp 1105-1117, Washington; Jul 1998.

18. Galesi VMN. Mortalidade por tuberculose no municipio de São Paulo, Análise De Uma Década, 1986 A 1995. São Paulo; 2001. [Dissertação de Mestrado - Faculdade de Saúde Pública da Universidade São Paulo].

19. Halar EM, Bell KR. Relação da reabilitação com a inatividade in Kottke FJ, Lehmann JF. Tratado de Medicina Física e Reabilitação de Krusen. $4^{a}$ Edição. São Paulo: Manole; 1994. 
20. Holick MF. Microgravity - induced bone loss. Will it limit human space exploration ? The Lancet, London; May 2000.

21. Holme C. Tuberculosis: story of medical failure. British Medical Journal; vol 317, pp1260; Oct 1998.

22. Hughes VA e col. Longitudinal muscle strength changes in older adults: influence of muscle mass, physical therapy, and health. The Journals of Gerontology; vol 56a, pp B209, Washington; May 2001.

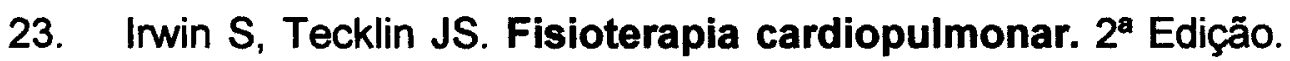
Brasil (São Paulo): Manole; 1994.

24. Kannus P. Immobilization or early mobilization after an acuta soft-tissue injury ? The Physician and Sports Medicine; vol 28, pp 55-63, Minneapolis; March 2000.

25. Lakatos EM, Marconi MA. Fundamentos de metodologia científica. $3^{\circledR}$ Edição.São Paulo: Atlas;1995.

26. Lerner $\mathrm{BH}$. Temporarily detained: tuberculous alcoholics in seattle, 1949 through 1960. American Journal of Public Health; vol 86, pp 257, Washington; Feb 1996. 
27. Li LC, Bombardier C. Physical therapy manangement of low back pain: an exporatory survey of therapist approaches. Physical Therapy; vol 81, pp 1018-1028, Washington; Apr 2001.

28. Mahoney JE, Sager MA, Jalaluddin M. New walking dependence associeted with hospitalization for acute medical illness : incidence and significance. The Journals of Gerontology; vol 53a, pp M307-M312, Washington; Jul 1998.

29. Masotti L e col. Pulmonary embolism often unrecognized in older patients. Geriatrics; vol 55, pp 87, Duluth; Nov 2000.

30. Mead S, Vallejo C. A century of the abuse of rest. Jama; vol. $182, n^{\circ} 4$, Oct. $27 ; 1962$.

31. Moffroid e col. Endurance training of trunk extensor muscles. Physical Therapy; vol 73, nº 1; January 1993.

32. Nogueira PA. Internações por tuberculose no Estado de São Paulo de 1984 a 1997. São Paulo; 2001 [Tese de Livre-Docência Faculdade de Saúde Pública da Universidade de São Paulo].

33. Oliveira MSC, Haddad ES, Koyama RC. Síndrome da imobilização in Greve JMA., Amatuzzi MM. Medicina de Reabilitação Aplicada à Ortopedia e Traumatologia. $1^{a}$ Edição. São Paulo: Roca; 1999. 
34. O'sullivan SB, Schmitz TJ. Fisioterapia - avaliaçăo e

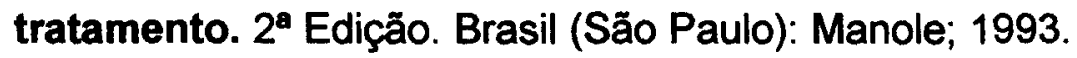

35. Raposo AC, Lopez RFA. Efeitos da imobilização prolongada e atividade fisica. Revista Digital; ano $8, n^{0} 50$. Buenos Aires; Julho, 2002. (www. efdeportes.Com)

36. Reichman LB. Whiter mycobacterium vaccae ? The Lancet: London; 1999.

37. Rosemberg J. Tuberculose - aspectos históricos, realidades, seu romantismo e transculturação. Boletim de Pneumologia Sanitária; vol 7, n², pp 5-29; Jul/Dez 1999.

38. Rumpf EA. Tuberculosis returns. Current Health 2; vol 19, pp 26: Highland Park; Oct 1992.

39. Saraiva J. Síndrome da imobilização uma entidade muitas vezes "esquecida". Revista de Saúde Amato Lusitano, ano 1, n 3, pp 41-45, Portugal; Out, Nov e Dez 1996.

40. Selikson S, Damus K, Hamerman D. Risk factors associeted with immobility. Journal American Geriatrics Society 36:707-712, 1988. 
41. Shaffer MA e col. Effects of immobilization on plantaflexion torque, fatique resistance, and functional ability Folowing ankle fracture. Physical Therapy; vol 80, pp 769-780: Washington; Aug 2000.

42. Sharpe $M$, Wessely $S$. Putting the rest cure to rest again. British Medical Journal; vol 316, pp 796: London; Mar 1998.

43. Toman $\mathrm{K}$. Tuberculosis case-finding and chemotherapy questions and answers. World Health Organization. Geneva; 1979.

44. Ministério da Saúde - Sistema de Informações Hospitalares do Sus (SIH/SUS). Média permanência por faixa etária 2 segundo sexo lista morbidade CID-10: Tuberculose Pulmonar. Período: Jul/2003 http://mww.datasus.gov.br 
ANEXO I 


\section{UNIVERSIDADE DE SÃO PAULO - FSP \\ DEPARTAMENTO DE EPIDEMIOLOGIA}

\section{TERMO DE CONSENTIMENTO LIVRE E ESCLARECIDO}

\section{PESQUISA: AVALIAÇÃO FISIOTERAPẼUTICA EM PACIENTES COM TUBERCULOSE PULMONAR SOB REGIME DE INTERNAÇÃO.}

(de acordo com a resolução 196 de 10/10/1996 do Conselho Nacional de Saúde)

$\mathrm{Eu}$ ac eito participar voluntariamente do estudo mencionado acima e que está sendo realizado pela pesquisadora Silvia de Oliveira Arpiani, mestranda da Faculdade de Saúde Pública da Universidade de São Paulo, sob orientação da Profa Dra. Margarida M. M. Brito de Almeida, da mesma Instituição.

Fui esclarecido dos seguintes pontos:

$\checkmark$ Objetivo da pesquisa: Observar o surgimento de alterações relacionadas com o imobilismo em pacientes com tuberculose pulmonar internados.

$\checkmark$ Riscos: minha participação não representa risco para minha integridade física, moral ou mental.

$\checkmark$ Beneficios: As informações obtidas nesta pesquisa poderão ser úteis cientificamente e, também, trarão informações sobre a minha saúde.

$\checkmark$ Método: darei meu depoimento através de entrevista individual e permitirei a realização de avaliação física.

$\checkmark$ Privacidade: Os dados individualizados serão confidenciais. Os resultados coletivos serão divulgados nos meios cientificos.

$\checkmark$ Desistência e acesso: fui informada e compreendo que posso, a qualquer tempo no decorrer do estudo, solicitar à pesquisadora informaçōes sobre o mesmo, ter acesso ao material individual transcrito ou desistir da pesquisa sem sofrer qualquer tipo de constrangimento.

$\checkmark$ Contato com a pesquisadora: Para dúvidas e esclarecimentos, o sr(a) poderá entrar em contato com a pesquisadora.

De acordo,

Assinatura do Participante / Responsável

Assinatura da Pesquisadora

contato: Silvia de Oliveira Arpiani - cel (11) $9821-4160$ / SP

email: arpiani@terra.com.br 
ANEXO 2 


\section{FICHA DE AVALIAÇÃO FISIOTERAPÊUTICA}

NOME:

RG:

LOCAL:

DATA DA AVALIAÇÃO:

DATA DE INTERNAÇÃO:

SEXO:

( ) MASCULINO

( ) FEMININO

IDADE:

ESTADO CIVIL

（ ) PRESENÇA DE COMPANHEIRO

（ ) AUSÊNCIA DE COMPANHEIRO

OCUPAÇÃO:

（ ) TRAB. REMUNERADO

（ ) DESEMPREGADO

( ) APOSENTADO

( ) NDA

GRAU DE ESCOLARIDADE:

( ) < OU IGUAL A 4 ANOS

( ) $>4$ ANOS 
TIPO DE MORADIA:

( ) ALVENARIA

( ) MISTA

( ) MADEIRA

TABAGISMO: ( )SIM( )NÃO

SE SIM QUANTOS ANOS/MAÇOS?

SE PAROU, HÁ QUANTO TEMPO PAROU?

QUANTO TEMPO FUMOU E QUANTOS MAÇOS FUMAVA?

ETILISMO: ( )SIM ( )NÃO

HÁ QUANTOS ANOS BEBE E QUAL A QUANTIDADE?

SE PAROU, HA QUANTO TEMPO PAROU?

QUANTO TEMPO BEBEU E QUANTO BEBIA?

DROGAS: ( )SIM ( )NÃO

SE SIM QUAL O TIPO DE DROGRA E QUAL A FREQUENCIA?

SE PAROU, HÁ QUANTO TEMPO PAROU?

POR QUANTO TEMPO USOU E QUAL TIPO DE DROGA QUE USOU? 


\section{SISTEMA MÚSCULOESQUELÉTICO}

\section{A)PESO}

(P):

B)ALTURA

(ALT.):

C) IMC:

( )DESNUTRIDO (abaixo de 18.5)

( )NORMAL (entre 18.5 e 24.9)

( )SOBREPESO (entre 25.0 e 29.9)

( )OBESO (entre 30.0 e 39.9)

( )OBESO MÓRBIDO (acima de 40.0)

D) TROF: 


\begin{tabular}{|l|l|}
\hline DIREITO & ESQUERDO \\
\hline OD & OE \\
\hline BD & BE \\
\hline$A D$ & AE \\
\hline CXD & CXE \\
\hline PD & PE \\
\hline PESCOÇO & \\
\hline TORAX & \\
\hline ABDOMEN & \\
\hline
\end{tabular}

E) GFM

\begin{tabular}{|l|l|}
\hline DIREITO & ESQUERDO \\
\hline MSD & MSE \\
\hline MID & MIE \\
\hline
\end{tabular}

F) UD ( ) PRESENTE REGIÃO:

( ) AUSENTE

G) DEAMBULAÇĀO 
SISTEMA CARDIOVASCULAR
A) FC:
( ) NORMOCÁRDIO ( FC ENTRE 60 E 80)
( ) TAQUICÁRDIO ( FC > 80)
( ) BRADICÁRDIO ( FC < 59)

\section{SISTEMA RESPIRATÓRIO}
A) EXPANSIBILIDADE: ( ) DIMINUÍDO
( ) NORMAL
B) AP
C) fr:

SISTEMA GASTROINTESTINAL

A) EVACUAÇÃO: ( ) PRESENTE

( ) AUSENTE

B) FLATOS

( ) PRESENTE

( ) AUSENTE

SISTEMA GENITURINÁRIO
A) DIURESE
$(\quad)<2$ VEZES AO DIA
( ) + 2 VEZES AO DIA 
C) DOR

( ) PRESENTE

( ) AUSENTE

D) SONDAS E CATÉTERES

\section{SISTEMA NERVOSO}

A) ESCALA ANÁLOGA DA DOR E MAPA CORPORAL

\section{Escala de Dor}

Sem dor

Muita dor

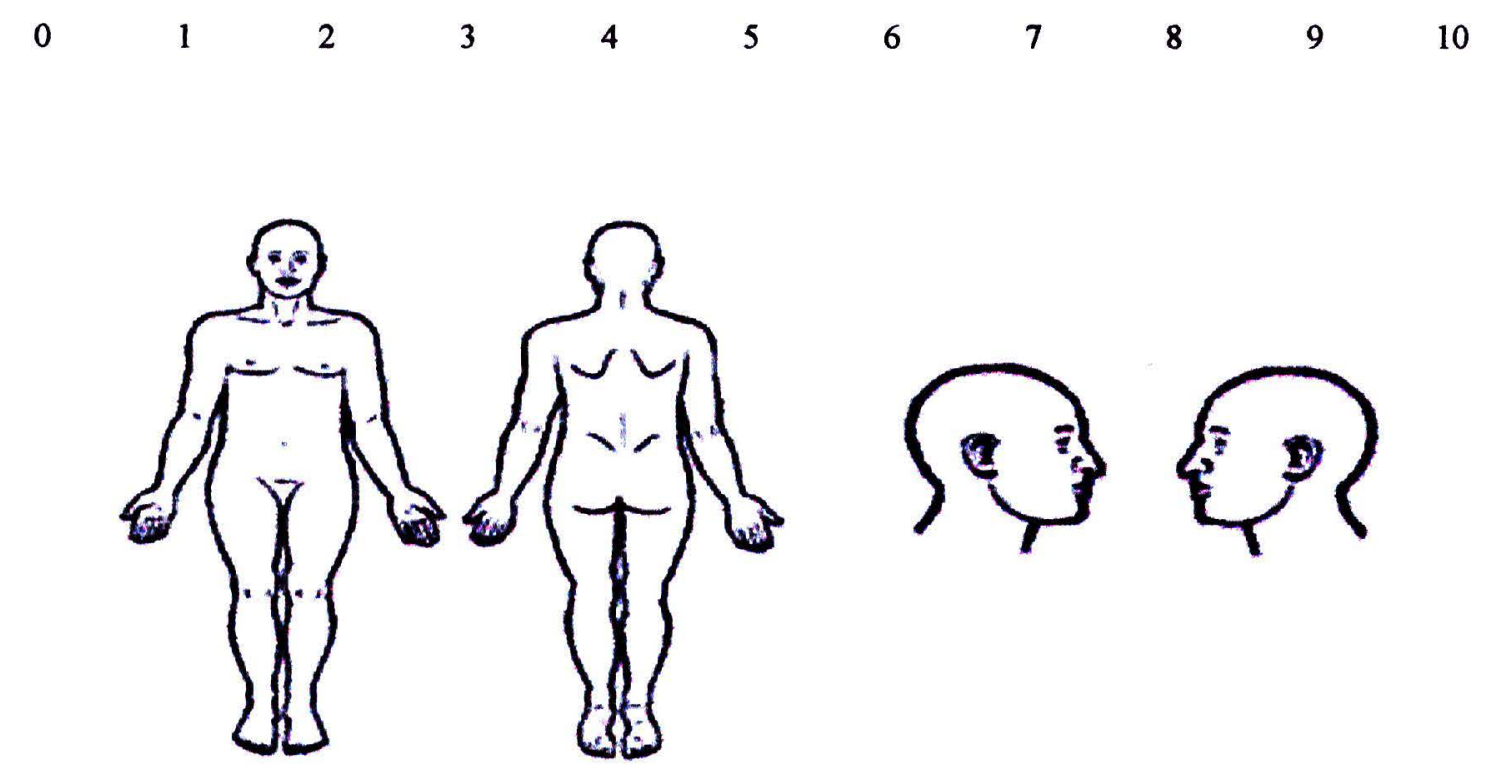




\section{FICHA DE AVALIAÇÃO FISIOTERAPÊUTICA}

NOME:

RG: LOCAL:

DATA DA AVALIAÇÃO:

PRIMEIRA QUE TEVE TUBERCULOSE?

SE JÁ TEVE QUANDO FOI?

TERMINOU O TRATAMENTO?

SE NÃO TERMINOU QUAL FOI O MOTIVO?

SISTEMA MÚSCULOESQUELÉTICO

A)PESO

(P):

B)ALTURA

(ALT.):

C) IMC: $\quad$ ( )DESNUTRIDO (abaixo de 18.5)

( )NORMAL (entre 18.5 e 24.9)

( )SOBREPESO (entre 25.0 e 29.9)

( )OBESO (entre 30.0 e 39.9)

( )OBESO MÓRBIDO (acima de 40.0) 


\begin{tabular}{|l|l|}
\hline DIREITO & ESQUERDO \\
\hline OD & OE \\
\hline BD & BE \\
\hline AD & AE \\
\hline CXD & CXE \\
\hline PD & PE \\
\hline PESCOÇO & \\
\hline TORAX & \\
\hline ABDOMEN & \\
\hline
\end{tabular}

D) TROF:

E) GFM

\begin{tabular}{|l|l|}
\hline DIREITO & ESQUERDO \\
\hline MSD & MSE \\
\hline MID & MIE \\
\hline
\end{tabular}

F) UD ( ) PRESENTE REGIÃO:

( ) AUSENTE

G) DEAMBULAÇÃO 
SISTEMA CARDIOVASCULAR
A) FC:
( ) NORMOCÁRDIO ( FC ENTRE 60 E 80 )
( ) TAQUICÁRDIO ( FC > 80)
( ) BRADICÁRDIO ( FC < 59)

\section{SISTEMA RESPIRATÓRIO}

A) EXPANSIBILIDADE: ( ) DIMINUÍDO

( ) NORMAL

B) AP

C) fr:

SISTEMA GASTROINTESTINAL

A) EVACUAÇÃO: ( ) PRESENTE

( ) AUSENTE

B) FLATOS ( ) PRESENTE

( ) AUSENTE

SISTEMA GENITURINÁRIO
A) DIURESE
( $)<2$ VEZES AO DIA
( ) + 2 VEZES AO DIA 
C) DOR

( ) PRESENTE

( ) AUSENTE

D) SONDAS E CATÉTERES

\section{SISTEMA NERVOSO}

B) ESCALA ANÁLOGA DA DOR E MAPA CORPORAL

\section{Escala de Dor}

Sem dor

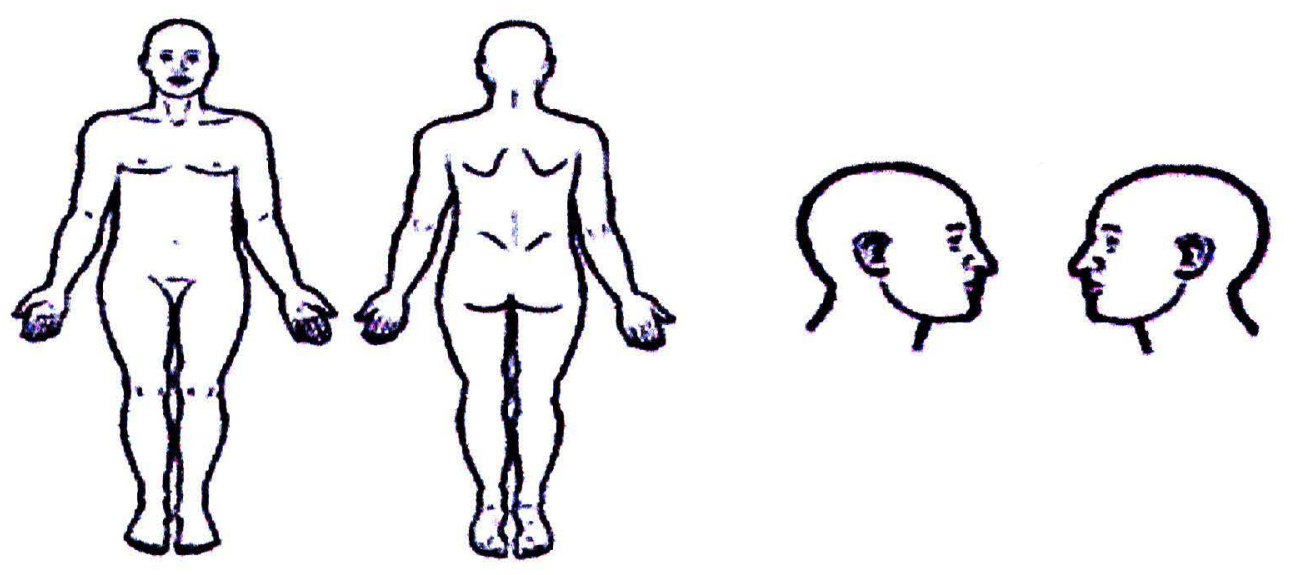


ANEXO 3 
ESCORE DO IMOBILISMO

>SISTEMA MÚSCULO-ESQUELÉTICO

\begin{tabular}{|c|c|c|}
\hline IMC & DEAMBULAÇÃO & LOMBALGIA \\
\hline DESNUTRIDO & ACAMADO & PRESENTE \\
5 & 3 & 2 \\
\hline OBESO MÓRBIDO & COM AUXÍlIO & AUSENTE \\
4 & 2 & 1 \\
\hline OBESO & NORMAL & - \\
3 & 1 & \\
\hline SOBREPESO & - & - \\
2 & - & - \\
\hline NORMAL & - & \\
\hline
\end{tabular}

\begin{tabular}{|c|c|c|c|c|c|c|c|}
\hline$\square$ & $\square$ & $\square$ & $\square$ & $\square$ & $\square$ & $\square$ & $\square$ \\
\hline $\mathbf{3}$ & $\mathbf{4}$ & $\mathbf{5}$ & $\mathbf{6}$ & $\mathbf{7}$ & $\mathbf{8}$ & $\mathbf{9}$ & $\mathbf{1 0}$ \\
\hline
\end{tabular}

D SISTEMA CARDIOVASCULAR

FREQUÊNCIA CARDÍACA TAQUICÁRDIO 3

BRADICÁRDIO

2

NORMORCÁRDIO

1

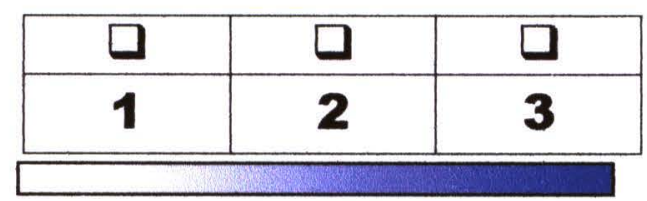

Normal

Imobilismo 
SISTEMA RESPIRATÓRIO

EXPANSIBILIDADE FREQUÊNCIA RESPIRATÓRIA DIMINú́DO TAQUIPNEICO 2 3

\begin{tabular}{|c|c|}
\hline NORMAL & 3 \\
1 & BRADIPNEICO \\
\hline- & EUPNEICO \\
& 1 \\
\hline
\end{tabular}

\begin{tabular}{|l|l|l|l|}
\hline$\square$ & $\square$ & $\square$ & $\square$ \\
\hline $\mathbf{2}$ & $\mathbf{3}$ & $\mathbf{4}$ & $\mathbf{5}$ \\
\hline
\end{tabular}

Normal Imobilismo

SISTEMA GASTROINTESTINAL EVACUAÇÕES CONSTIPAÇÃO 3

DIARRÉIA

2

NORMAL

1

\begin{tabular}{|l|l|l|}
\hline$\square$ & $\square$ & $\square$ \\
\hline $\mathbf{1}$ & $\mathbf{2}$ & $\mathbf{3}$ \\
\hline
\end{tabular}

Normal

Imobilismo 


\section{SISTEMA GENITURINÁRIO}

\section{DIURESE}

\section{RUIM}

3

\section{REGULAR}

2

RUIM

1

\begin{tabular}{|l|l|l|}
\hline$\square$ & $\square$ & $\square$ \\
\hline $\mathbf{1}$ & $\mathbf{2}$ & $\mathbf{3}$ \\
\hline
\end{tabular}

Normal Imobilismo

SISTEMA NERVOSO

\begin{tabular}{|c|c|}
\hline DOR & NEUROPATIA PERIFÉRICA \\
\hline DOR FORTE (7 - 10) & PRESENTE \\
3 & 2 \\
\hline DOR MODERADA (4 - 6) & AUSENTE \\
2 & 1 \\
\hline DOR FRACA (1 - 3) & - \\
1 & - \\
\hline SEM DOR (0) & \\
\hline
\end{tabular}

\begin{tabular}{|l|l|l|l|l|}
\hline$\square$ & $\square$ & $\square$ & $\square$ & $\square$ \\
\hline $\mathbf{1}$ & $\mathbf{2}$ & $\mathbf{3}$ & $\mathbf{4}$ & $\mathbf{5}$ \\
\hline
\end{tabular}


ANEXO 4 
- Variação final dos resultados de todos os pacientes com tuberculose pulmonar, Estado de São Paulo, de junho de 2002 e fevereiro de 2003.

\begin{tabular}{|c|c|c|c|}
\hline PACIENTE & PRÉ & Pós & VARIAÇÃO \\
\hline 1 & 23 & 21 & +0.09 \\
\hline 2 & 17 & 18 & -0.06 \\
\hline 3 & 17 & 19 & -0.12 \\
\hline 4 & 19 & 19 & 0 \\
\hline 5 & 23 & 21 & +0.09 \\
\hline 6 & 19 & 19 & 0 \\
\hline 7 & 11 & 15 & -0.36 \\
\hline 8 & 12 & 13 & -0.08 \\
\hline 9 & 12 & 14 & -0.16 \\
\hline 10 & 22 & 25 & -0.13 \\
\hline 11 & 27 & 20 & +0.26 \\
\hline 12 & 19 & 22 & -0.15 \\
\hline 13 & 23 & 21 & +0.09 \\
\hline 14 & 15 & 16 & -0.06 \\
\hline 15 & 17 & 18 & -0.06 \\
\hline 16 & 16 & 18 & -0.12 \\
\hline 17 & 16 & 14 & +0.12 \\
\hline 18 & 14 & 14 & 0 \\
\hline 19 & 16 & 17 & -0.06 \\
\hline 20 & 15 & 13 & +0.13 \\
\hline 21 & 12 & 11 & +0.08 \\
\hline 22 & 15 & 17 & -0.13 \\
\hline 23 & 14 & 11 & +0.21 \\
\hline 24 & 11 & 13 & -0.18 \\
\hline 25 & 16 & 12 & +0.25 \\
\hline TOTAL & 421 & 421 & 0 \\
\hline MÉDIA & 16,84 & 16,84 & 0 \\
\hline
\end{tabular}


- Distribuição, em dias, do tempo de internação de indivíduos internados com tuberculose pulmonar, Estado de São Paulo, de junho de 2002 e fevereiro de 2003.

\begin{tabular}{|c|c|}
\hline PACIENTE & TEMPO DE INTERNAÇĀO \\
\hline 1 & 16 \\
\hline 2 & 19 \\
\hline 3 & 50 \\
\hline 4 & 165 \\
\hline 5 & 10 \\
\hline 6 & 14 \\
\hline 7 & 64 \\
\hline 8 & 11 \\
\hline 9 & 163 \\
\hline 10 & 732 \\
\hline 11 & 40 \\
\hline 12 & 170 \\
\hline 13 & 224 \\
\hline 14 & 33 \\
\hline 15 & 456 \\
\hline 16 & 88 \\
\hline 17 & 170 \\
\hline 18 & 174 \\
\hline 19 & 146 \\
\hline 20 & 82 \\
\hline 21 & 30 \\
\hline 22 & 67 \\
\hline 23 & 161 \\
\hline 24 & 137 \\
\hline 25 & 107 \\
\hline TOTAL & 3329 \\
\hline MÉDIA & 133,16 \\
\hline
\end{tabular}




\begin{tabular}{|c|c|c|c|c|c|c|c|c|c|c|c|c|c|c|c|c|c|c|c|c|}
\hline \multirow{2}{*}{ PACIENTE } & \multicolumn{2}{|c|}{ IMC } & \multicolumn{2}{|c|}{ DEAMB } & \multicolumn{2}{|c|}{ LOMBAL } & \multicolumn{2}{|c|}{ FC } & \multicolumn{2}{|c|}{ FR } & \multicolumn{2}{|c|}{ EXP } & \multicolumn{2}{|c|}{ EVAC } & \multicolumn{2}{|c|}{ DIURESE } & \multicolumn{2}{|c|}{ DOR } & \multicolumn{2}{|c|}{ NEUROP } \\
\hline & Pré & Pós & Pré & Pós & Pré & Pós & \begin{tabular}{|l|} 
Pré \\
\end{tabular} & Pós & Pré & Pós & Pré & Pós & Pré & Pós & Pré & Pós & Pré & Pós & Pré & Pós \\
\hline 1 & 5 & 5 & 1 & 1 & 1 & 1 & 3 & 3 & 3 & 3 & 2 & 2 & 2 & 1 & 1 & 1 & 3 & 3 & 2 & 1 \\
\hline 2 & 5 & 5 & 2 & 1 & 1 & 1 & 1 & 3 & 1 & 3 & 2 & 2 & 3 & 1 & 1 & 1 & 0 & 0 & 1 & 1 \\
\hline 3 & 1 & 1 & 2 & 2 & 1 & 1 & 3 & 3 & 1 & 3 & 2 & 2 & 1 & 1 & 1 & 1 & 3 & 3 & 2 & 2 \\
\hline 4 & 5 & 5 & 1 & 2 & 1 & 1 & 1 & 3 & 3 & 3 & 2 & 2 & 2 & 1 & 1 & 1 & 2 & 0 & 1 & 1 \\
\hline 5 & 5 & 5 & 2 & 2 & 2 & 1 & 3 & 3 & 3 & 3 & 2 & 2 & 3 & 1 & 1 & 1 & 1 & 2 & 1 & 1 \\
\hline 6 & 5 & 5 & 2 & 2 & 1 & 1 & 3 & 3 & 3 & 3 & 2 & 2 & 1 & 1 & 1 & 1 & 0 & 0 & 1 & 1 \\
\hline 7 & 1 & 1 & 1 & 1 & 1 & 2 & 1 & 1 & 1 & 3 & 2 & 2 & 1 & 1 & 1 & 1 & 1 & 2 & 1 & 1 \\
\hline 8 & 1 & 1 & 1 & 1 & 1 & 1 & 1 & 3 & 1 & 1 & 1 & 1 & 1 & 1 & 1 & 1 & 3 & 2 & 1 & 1 \\
\hline 9 & 1 & 1 & 1 & 1 & 1 & 1 & 3 & 3 & 2 & 3 & 1 & 2 & 1 & 1 & 1 & 1 & 0 & 0 & 1 & 1 \\
\hline 10 & 5 & 5 & 3 & 3 & 2 & 2 & 1 & 1 & 1 & 2 & 2 & 2 & 1 & 3 & 2 & 2 & 3 & 3 & 2 & 2 \\
\hline 11 & 5 & 5 & 3 & 2 & 1 & 1 & 3 & 3 & 3 & 3 & 2 & 2 & 3 & 1 & 2 & 2 & 3 & 0 & 2 & 1 \\
\hline 12 & 5 & 5 & 2 & 2 & 1 & 1 & 3 & 3 & 3 & 3 & 2 & 1 & 1 & 1 & 1 & 1 & 0 & 3 & 1 & 2 \\
\hline 13 & 5 & 5 & 3 & 3 & 1 & 1 & 1 & 1 & 3 & 3 & 2 & 1 & 3 & 1 & 2 & 2 & 2 & 3 & 1 & 1 \\
\hline 14 & 1 & 1 & 1 & 1 & 1 & 1 & 3 & 3 & 3 & 1 & 1 & 1 & 3 & 3 & 1 & 1 & 0 & 2 & 1 & 2 \\
\hline 15 & 1 & 5 & 2 & 2 & 2 & 1 & 1 & 3 & 3 & 1 & 2 & 2 & 1 & 1 & 2 & 2 & 2 & 0 & 1 & 1 \\
\hline 16 & 1 & 1 & 1 & 1 & 2 & 1 & 1 & 3 & 3 & 3 & 1 & 2 & 1 & 1 & 1 & 1 & 3 & 3 & 2 & 2 \\
\hline 17 & 1 & 1 & 2 & 2 & 1 & 1 & 3 & 3 & 3 & 3 & 2 & 1 & 1 & 1 & 2 & 1 & 0 & 1 & 1 & 1 \\
\hline 18 & 1 & 1 & 1 & 1 & 1 & 1 & 1 & 3 & 3 & 3 & 2 & 2 & 1 & 1 & 1 & 1 & 2 & 0 & 1 & 1 \\
\hline 19 & 1 & 1 & 2 & 2 & 1 & 2 & 1 & 1 & 3 & 3 & 1 & 1 & 1 & 1 & 1 & 1 & 3 & 3 & 2 & 2 \\
\hline 20 & 1 & 1 & 1 & 1 & 2 & 1 & 3 & 1 & 1 & 3 & 1 & 1 & 1 & 1 & 2 & 1 & 2 & 2 & 1 & 1 \\
\hline 21 & 1 & 1 & 1 & 1 & 1 & 1 & 3 & 3 & 1 & 1 & 1 & 1 & 1 & 1 & 1 & 1 & 1 & 0 & 1 & 1 \\
\hline 22 & 1 & 1 & 1 & 2 & 1 & 1 & 1 & 1 & 3 & 3 & 2 & 2 & 1 & 1 & 1 & 1 & 3 & 3 & 1 & 2 \\
\hline 23 & 1 & 1 & 1 & 1 & 1 & 1 & 1 & 1 & 3 & 3 & 2 & 1 & 1 & 1 & 1 & 1 & 1 & 0 & 2 & 1 \\
\hline 24 & 1 & 1 & 1 & 1 & 1 & 1 & 1 & 1 & 1 & 1 & 1 & 1 & 1 & 1 & 1 & 1 & 1 & 3 & 2 & 2 \\
\hline 25 & 5 & 1 & 1 & 1 & 1 & 1 & 3 & 1 & 1 & 3 & 2 & 2 & 1 & 1 & 1 & 1 & 0 & 0 & 1 & 1 \\
\hline TOTAL & 65 & 65 & 39 & 39 & 29 & 28 & 49 & 57 & 56 & 64 & 42 & 40 & 37 & 29 & 31 & 29 & 39 & 38 & 33 & 33 \\
\hline MÉDIA & 2.60 & 2.60 & 1.56 & 1.56 & 1.16 & 1.12 & 1.96 & 2.28 & 2.24 & 2.56 & 1.68 & 1.60 & 1.48 & 1.16 & 1.24 & 1.16 & 1.56 & 1.52 & 1.32 & 1.32 \\
\hline VARIAÇĀO & & & & 0 & +0 & & -0 & 16 & & & & & & & & & & & & 0 \\
\hline
\end{tabular}

